\begin{tabular}{|c|c|}
\hline Title & $\begin{array}{l}\text { Spleen selective enhancement of transfection activities of plasmid DNA driven by octaarginine and an ionizable lipid } \\
\text { and its implications for cancer immunization }\end{array}$ \\
\hline Author(s) & Kimura, Seigo; Khalil, Ikramy A .; Elewa, Y aser H. A .; Harashima, Hidey oshi \\
\hline Citation & $\begin{array}{l}\text { Journal of controlled release, 313, 70-79 } \\
\text { https://doi.org/10.1016/.jconrel.2019.09.009 }\end{array}$ \\
\hline Issue Date & 2019-11-10 \\
\hline Doc URL & http:/hdl.handle.net/2115/79729 \\
\hline Rights & $\begin{array}{l}\text { O2019. This manuscript version is made available under the CC-BY-NC-ND } 4.0 \text { license } \\
\text { http://reativecommons.org/icenses/by-nc-nd/4.0/ }\end{array}$ \\
\hline Rights(URL) & https://creativecommons.org/icenses/by-nc-nd/4.0/ \\
\hline Type & article (author version) \\
\hline File Information & WoS_91817_Harashima.pdf \\
\hline
\end{tabular}

Instructions for use 
Journal of Controlled Release

Research Article - Ms. Ref. No.: JCR-D-19-00580

\section{Spleen Selective Enhancement of Transfection Activities of Plasmid DNA Driven by Octaarginine and an Ionizable Lipid and its Implications for Cancer Immunization}

Seigo Kimura ${ }^{\mathrm{a}}$, Ikramy A. Khalil ${ }^{\mathrm{a}, \mathrm{b}, *}$, Yaser H. A. Elewa ${ }^{\mathrm{c}, \mathrm{d}}$, and Hideyoshi Harashima ${ }^{\mathrm{a}, \mathrm{e}, *}$

${ }^{a}$ Laboratory of Innovative Nanomedicine, Faculty of Pharmaceutical Sciences, Hokkaido University, Kita-12, Nishi-6, Kita-ku, Sapporo 060-0812, Japan

${ }^{b}$ Department of Pharmaceutics, Faculty of Pharmacy, Assiut University, Assiut 71526, Egypt

${ }^{c}$ Department of Histology and Cytology, Faculty of Veterinary Medicine, Zagazig University, Zagazig, Egypt

${ }^{d}$ Laboratory of Anatomy, Department of Biomedical Sciences, Graduate School of Veterinary

Medicine, Hokkaido University, Kita 18, Nishi 9, Kita-ku, Sapporo 060-0818, Japan

${ }^{e}$ Laboratory for Molecular Design of Pharmaceutics, Faculty of Pharmaceutical Sciences, Hokkaido University, Kita-12, Nishi-6, Kita-ku, Sapporo 060-0812, Japan

*Corresponding authors at: Faculty of Pharmaceutical Sciences, Hokkaido University, Kita-12, Nishi-6, Kita-ku, Sapporo 060-0812, Japan Tel +81-11-706-3919; Fax +81-11-706-4879. E-mail addresses: harasima@ pharm.hokudai.ac.jp (H. Harashima), ikramy@aun.edu.eg (I. A. Khalil) 


\begin{abstract}
Efficiently delivering plasmid DNA (pDNA) to the spleen is particularly significant for DNA immunization. However, increasing the efficiency of gene expression in spleen cells for achieving a therapeutic effect remains a serious challenge. An ideal spleen-targeted system should avoid liver uptake and should efficiently transfect specific functional spleen cells. Here, we report on pDNA nanocarriers with enhanced transfection in spleen cells driven by synergism between an octaarginine (R8) peptide and YSK05; a pH-responsive ionizable lipid. A doublecoating design is essential for enhancing spleen selective transfection which is significantly affected by the total amount of lipid and the composition of the outer coat. The optimized R8/YSK system shows a high gene expression in the spleen with a high spleen/liver ratio and a surprising ability to target spleen B cells. Compared to other organs, the high spleen activity cannot be explained based on the amount of pDNA delivered to each organ, indicating that the system is extremely efficient in transfecting spleen cells. The system can be used in cancer immunization where a strong anti-tumor effect was observed in mice immunized with the R8/YSK system encapsulating antigen-encoding pDNA. The R8/YSK system holds great promise for future applications in the field of DNA vaccination.
\end{abstract}

KEYWORDS: gene delivery, pDNA, YSK05, R8, spleen 


\section{Graphical Abstract}

The R8/YSK-MEND shows a high gene expression in the spleen with a high spleen/liver ratio and B cell targeting. A strong anti-tumor effect was observed in mice immunized with R8/YSKMEND encapsulating antigen-encoding pDNA.
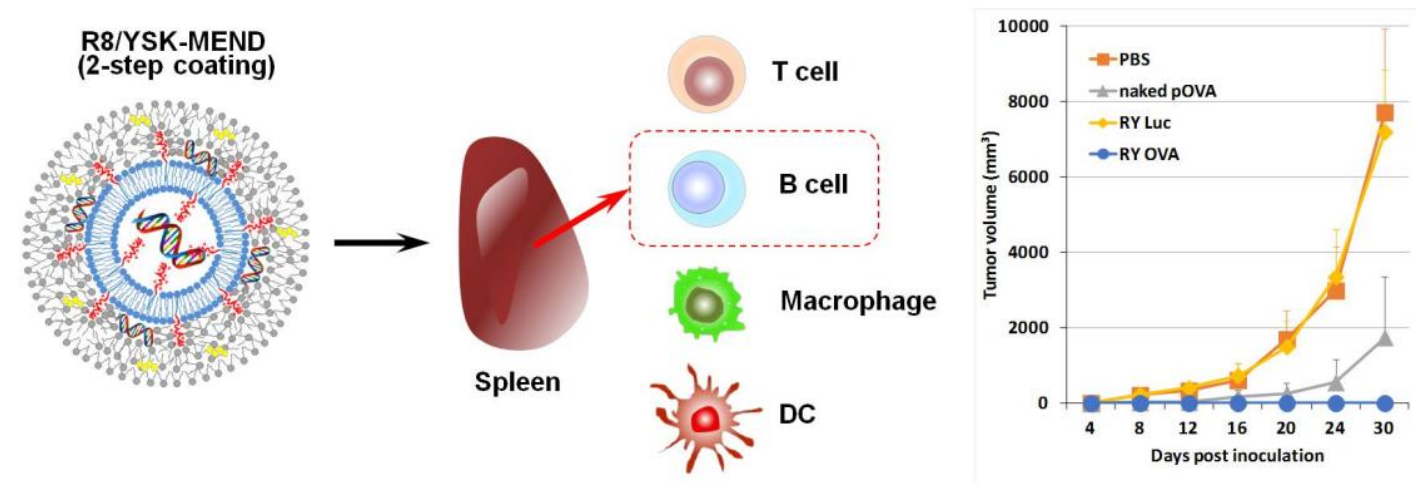


\section{Introduction}

Gene therapy has considerable promise as an innovative nanomedicine for the treatment of various incurable diseases [1-3]. To realize gene therapy, it is necessary to deliver therapeutic genes to the target sites and for them to be expressed in doses sufficient to produce a therapeutic effect. However, unlike conventional low molecular weight drugs, for gene therapy to be successfully applied, high molecular weight nucleic acids face a number of intracellular and extracellular barriers, including in vivo instability, low membrane permeability and the elicitation of an immune response [4-6]. In addition, it is also necessary to consider the intracellular pharmacokinetics of the gene vectors to optimize the delivery of the therapeutic gene to its intracellular target site [7]. Most of the intravenously injected gene-carrying nanoparticles (NPs) are rapidly cleared from the blood through uptake by the liver and spleen, which is the biggest hurdle in terms of successfully delivering a gene to other diseased organs [6-8]. However, these two organs are particularly good candidates for gene therapy, even for diseases that are associated with other organs. Immune cells in the spleen are particularly attractive targets for gene therapy for the treatment of various immune-related diseases including allergies, inflammation, autoimmune diseases, infections and cancer [8, 9]. Dendritic cells (DCs) in the spleen can be targeted with different antigens to activate antigen-specific $\mathrm{T}$ cells making the process a potent strategy for cancer immunotherapy [10, 11]. B cells are involved in secreting antibodies and different cytokines to regulate inflammation and to fight infections. B cells can also act as antigen presenting cells (APCs) to stimulate T cell production. Modulating B cells in the spleen is an attractive approach for the treatment of autoimmune diseases, allergies and specific types of cancer [9, 12-14]. Even CD8+ T cells in the lymphoid tissues can be targeted with immunomodulatory compounds for augmenting T cell function [15]. 
The efficient delivery of plasmid DNA (pDNA) to the spleen is particularly significant in terms of developing DNA vaccines. Transfecting spleen cells with antigen-encoded pDNA generates specific antigens that then stimulate the immune system. In addition, DNA can itself function as an adjuvant to trigger cellular immunity via activating the stimulator of interferon genes pathway [16]. This means that DNA vaccines have the potential for both expressing specific antigens and activating the immune system as an adjuvant. DNA vaccinations have shown promising antitumor immune responses in clinical trials [17, 18]. Although the physiology of the spleen makes it accessible to systemically administered gene vectors [8], the level of gene expression in spleen cells needs to be increased if a therapeutic effect is to be achieved. An ideal spleen targeted gene delivery system should avoid liver uptake and should deliver the therapeutic gene to a large percentage of non-phagocytic functional cells in the spleen. Compared to the liver, few studies concerning the in vivo efficient delivery of pDNA to the spleen have been reported [19-21]. Considering the ease of delivering gene carriers to the spleen, there is a need for a clear strategy to enhance nuclear delivery for maximizing pDNA gene expression in spleen cells.

Lipid nanoparticles for DNA delivery are the most common non-viral systems used for in vivo gene delivery $[22,23]$. We previously developed a multifunctional envelope-type nano device (MEND) as an artificial carrier for delivering different genes to target sites [24-26]. The MEND system is composed of a nucleic acid core condensed by polycations and coated with a lipid membrane modified with various functional elements. Different types of MEND systems can be used to efficiently deliver pDNA and siRNA to different organs such as the liver and lung [27-31]. In a recently study, we combined two functional devices; octaarginine (R8), a cell penetrating peptide (CPP), and YSK05, a pH-sensitive ionizable lipid, in one system by a novel 
preparation method based on a double membrane coating [32]. The R8 peptide and the YSK05 lipid functioned synergistically in the double coated nanoparticles, resulting in a dramatically improved in vitro gene expression. The double coating strategy was critical for achieving high gene expression efficiency in HeLa cells. A controlled amount of the R8 peptide located in the inner coat significantly increased cellular uptake, endosomal escape and the nuclear delivery of pDNA. While positively charged conventional R8-MENDs are mainly delivered to the liver [27], we hypothesize that the double-coated R8/YSK-MEND would be a promising candidate for the in vivo delivery of pDNA to the spleen. The amount and location of the R8 were carefully controlled so as to produce non-positively charged NPs which would not be expected to be extensively taken up by the liver when systemically administered $[8,33]$. Furthermore, the diameter of the double-coated NPs is generally $>150 \mathrm{~nm}$, which would limit the amount that passes the liver fenestrae. The double-coating design results in more rigid NPs due to the compactness of the DNA within the two lipid layers and these rigid NPs would be expected to more specifically accumulate in the spleen. In addition, the double-coating design allows the inclusion of the $\mathrm{R} 8$ peptide in the inner coat. This may alter the interactions with protein corona which may be relevant to specific spleen delivery.

In this study, we tested the applicability of the R8/YSK-MEND system for in vivo gene delivery after intravenous (IV) administration. The biodistribution of different MENDs, synergism between R8 and YSK05 in gene expression, and the role of the double-coating were evaluated. The system showed a high gene expression in the spleen where the synergism between R8 and YSK05 was confirmed in vivo. In addition, the presence of R8 and the double coating design were essential for the selective enhancement of spleen transfection. We further optimized the system in terms of the amount of lipid used and the composition needed. The 
optimized R8/YSK system showed an improved gene expression in the spleen with a high spleen/liver ratio and was successfully used for DNA vaccination. A strong anti-tumor effect was observed in mice immunized with the R8/YSK system, indicating that this system holds great promise for future applications in the field of DNA vaccination. 


\section{Materials and Methods}

\subsection{Materials}

Dioleoyl-phosphoethanolamine (DOPE), 1,2-dioleoyl-3-trimethylammonium-propane (DOTAP), and cholesterol (Chol) were purchased from Avanti Polar Lipids (Alabaster, AL). Dimyristoylmethoxypolyethylene glycol 2000 (DMG-PEG) was purchased from the NOF CORPORATION (Tokyo, Japan). Stearyl-octaarginine (STR-R8) was purchased from Toray Research Center, Inc. (Tokyo-Japan). YSK05 was synthesized as previously described [34]. The reporter plasmid pcDNA3.1(+)-luc (7037 bp) encoding the firefly luciferase gene was purified using a Qiagen Endofree Plasmid Mega Kit (Qiagen GmbH, Helden, Germany). The luciferase assay reagent and reporter lysis buffer were obtained from Promega Co. (Madison, USA). All other materials were of reagent-grade and commercially available.

\subsection{Animals}

Four-week-old male ICR mice or female C57BL6J mice were purchased from Sankyo Labo service (Shizuoka, Japan). The experimental protocols were reviewed and approved by the Hokkaido University Animal Care Committee in accordance with the "Guide for the Care and Use of Laboratory Animals". In all experiments, the animals were used without fasting.

\subsection{Preparation of MENDs}

MENDs were prepared by the lipid hydration method, as previously described [24]. For the optimized MEND, the total amount of lipid used was 640 nmol of lipids for $30 \mu \mathrm{g}$ of pDNA (the nitrogen to phosphate (NP) ratio was estimated to be $\sim 3.56)$. The lipids used in the first coat (DOPE/STR-R8 = 95.5/4.5; total $320 \mathrm{nmol}$ ) were dissolved in ethanol and evaporated to form a lipid film (tube 1). The lipids used in the second coat (YSK05/Chol/DMG-PEG = 68.5/28.5/3; total $320 \mathrm{nmol}$ ) were dissolved in ethanol and evaporated to form a second lipid film (tube 2). 
The pDNA $(30 \mu \mathrm{g})$ was dissolved in $500 \mu \mathrm{l}$ of HEPES buffer $(10 \mathrm{mM}, \mathrm{pH}=4)$ and the solution was used to hydrate the lipid film in tube 1 for $15 \mathrm{~min}$ at room temperature. The tube was sonicated in a bath type sonicator and then incubated for $30 \mathrm{~min}$ at room temperature. The contents were then transferred to tube 2 where they were incubated with the second lipid film for $15 \mathrm{~min}$. The second tube was then sonicated for $\sim 1 \mathrm{~min}$ and incubated for $30 \mathrm{~min}$ at room temperature and the $\mathrm{pH}$ was adjusted to 7.4. The NP ratio of the final preparation was estimated to be $\sim 1.28$. MENDs were characterized by measuring the diameter and surface charge using a Zeta-sizer Nano ZS ZEN3600 instrument (Malvern, UK). A Picogreen assay kit (Molecular Probes, Eugene, USA) was used to determine the final pDNA concentration and the encapsulation efficiency (EE) according to the manufacturer's protocol.

\subsection{In vivo luciferase assay}

5-6-week-old ICR mice were treated with the MEND (tail vain injection) containing $30 \mu \mathrm{g}$ of pDNA. The mice were sacrificed $6 \mathrm{hr}$ after the treatment, and the liver, lungs, and spleen were collected. The collected organs were washed with saline, weighed, and minced with scissors. A $0.2 \mathrm{~g}$ sample of liver tissue and the other whole collected organs were completely homogenized using a Precellys 24 homogenizer in $1 \mathrm{~mL}$ of Lysis Buffer (100 mM Tris-HCl, 2 mM EDTA, $0.1 \%$ Triton $\mathrm{X}-100, \mathrm{pH} 7.8)$. After centrifugation at $15000 \mathrm{rpm}$ for $10 \mathrm{~min}$ at $4^{\circ} \mathrm{C}$, a $10 \mu \mathrm{l}$ aliquot of the supernatant was examined for luciferase activity. The spleen/liver (S/L) ratio was calculated by dividing the luciferase activity in the spleen by the activity in the liver. This ratio was used as an indication of the spleen selective transfection (the higher this ratio, the higher is the spleen selectivity).

\subsection{Biodistribution}


DiD labeled MENDs containing $30 \mu \mathrm{g}$ pDNA (DiD is used as $1 \mathrm{~mol} \%$ of total lipid) were injected into the tail vein of 4-5-week-old ICR mice. The total amount of lipid injected was estimated as $\sim 914-1067 \mathrm{nmol}$ based on the EE of pDNA ( 60-70\%). At $6 \mathrm{hr}$ after injection, the liver, lungs, and spleen were collected, weighed and minced with scissors. Approximately $25 \mathrm{mg}$ of each organ was transferred to micro-tubes (SARSTEDT) containing beads and homogenized using a Precellys 24 homogenizer in a $1 \%$ sodium dodecyl sulfate (SDS) solution. The samples were then centrifuged at $15000 \mathrm{rpm}$ for $10 \mathrm{~min}$ at $4^{\circ} \mathrm{C}$. A $100 \mu \mathrm{l}$ aliquot of supernatant was taken to measure DiD fluorescent intensity using Enspire 2300 multilabel reader (Perkin Elmer) with $\mathrm{Ex} / \mathrm{Em}=650 / 680 \mathrm{~nm}$. Tissue accumulation of the MENDs was calculated as $\% \mathrm{ID} / \mathrm{g}$ of tissue based on the standard calibration curve of the DiD fluorescent intensity from the MENDs and non-treated mouse tissues.

\subsection{Determination of Spleen cell type}

4-5-week-old ICR mice were injected into the tail vein with MENDs labeled with DiD (1 mol\% of total lipid) At $6 \mathrm{hr}$ after injection, the spleen was collected and splenocytes were isolated from the spleen in $5 \mathrm{~mL}$ of RPMI1640 supplemented with $10 \%$ heat-inactivated fetal bovine serum (FBS), penicillin (100 U/mL), streptomycin $(100 \mu \mathrm{g} / \mathrm{mL}), 10 \mathrm{mM}$ HEPES, $100 \mathrm{mM}$ sodium pyruvate and $50 \mathrm{nM}$ 2-mercaptoethanol (gibco). The cell suspension was passed through a nylon mesh to remove any cell aggregates. After centrifugation at $2000 \mathrm{~g}$ for $5 \mathrm{~min}$ at $4{ }^{\circ} \mathrm{C}$, the supernatant was removed and $1 \mathrm{~mL}$ of ACK lysing buffer was added to the cell precipitates, followed by incubation at room temperature for $5 \mathrm{~min}$. A $9 \mathrm{~mL}$ portion of RPMI medium was added to cells and they were then centrifuged at $2000 \mathrm{~g}$ for $5 \mathrm{~min}$ at $4^{\circ} \mathrm{C}$. The centrifugation and re-suspension in RPMI were repeated twice. The final cell suspension was passed through a

nylon mesh to remove any cell aggregates. The number of cells was counted and adjusted to $10^{6}$ 
cells/tube. Cells were suspended in FACS buffer $(1 \mathrm{~g} / \mathrm{L} \mathrm{NaN} 3,5 \mathrm{~g} / \mathrm{L} \mathrm{BSA}$ in PBS (-)), incubated with Fc-receptor blocking anti-mouse CD16/32 for 10 min on ice, then incubated with $1 \mu \mathrm{g}$ FITC anti-mouse/human CD45R/B220 and $0.25 \mu \mathrm{g}$ PE anti-mouse CD3, or $0.25 \mu \mathrm{g}$ FITC antimouse F4/80 and $0.25 \mu \mathrm{g}$ PE anti-mouse CD11c for 30 min on ice. After incubation, the cells were washed with FACS buffer and passed through a mesh to remove any cell aggregates, then analyzed by Gallios (flow cytometer). The expression of CD45R/B220 and CD3, or F4/80 and CD11c were determined after the gating of DiD positive cells to determine the type of spleen cells that had taken up the MENDs.

\subsection{Anti-tumor effect}

The pDNA encoding antigen (ovalbumin; OVA) was a generous gift from Prof. Tanaka H (Tiba University). C57BL/6 mice were intravenously injected with the R8/YSK-MEND encapsulating the pDNA for immunization on 1 and 2 weeks before tumor inoculation ( $20 \mu \mathrm{g} \mathrm{pDNA} / \mathrm{mouse})$. Thereafter, $5 \times 10^{5}$ antigen (OVA)-expressing E.G7-OVA cells were subcutaneously injected. Tumor volume was calculated by the following formula: (major axis $\times$ minor axis $\left.{ }^{2}\right) \times 0.52$.

\subsection{Statistical analysis}

Comparisons between multiple treatments were made utilizing the one-way analysis of variance (ANOVA) followed by Bonferroni or Student-Newman-Keuls test. Pair-wise comparisons between treatments were made using a two-tail Student t-test. A P-value of $<0.05$ was considered to be significant $(* ; \mathrm{P}<0.05, * * ; \mathrm{P}<0.01)$. 


\section{Results and Discussion}

\subsection{Comparison of YSK-MEND and R8/YSK-MEND}

First, the in vivo gene expression of the previously optimized R8/YSK-MEND [32] was evaluated. We prepared a double-coated R8/YSK-MEND in which pDNA is first coated with a lipid layer composed of a mixture of DOPE and R8 and then further coated with a second lipid layer composed of YSK05, cholesterol and DMG-PEG. We compared the activity of the R8/YSK-MEND (RY) with YSK-MEND system lacking R8 (Y). The diameters and charges of the various MENDs are shown in Table 1. Transmission electron microscopy (TEM) images of the R8/YSK-MEND prepared with 1-step or 2-step coating are shown in Fig. S1. While most of the 1-step coated MENDs were observed to be a spherical solid core, there were numerous solid cores that were covered with additional lipid layers in the case of 2-step coating. The 2-step coating particles appeared in the form of typical core-shell structures. The different MENDs were administered to mice by IV injection. At $6 \mathrm{hr}$ after injection, the liver, lung and spleen were collected and the luciferase activity in each organ was measured (Fig. 1). The activity of the R8/YSK-MEND was higher than that of the YSK-MEND, especially in the spleen ( 11 fold). This result indicates that R8 modification results in improved transfection activities of the YSKMEND in vivo, which is consistent with the in vitro results [32], although the improvement in the case of the R8/YSK-MEND compared to YSK-MEND was much higher in vitro ( 700 fold). We previously proposed that the mechanism for this in vitro improvement can be attributed to the presence of R8, which improved cellular uptake, endosomal escape and nuclear delivery. Although R8 is thought to be located in the inner coat, a small fraction may be expressed on the outer layer due to lipid mixing during the second coating process. In a previous study, we showed that even a small fraction of R8 expressed on the surface can significantly enhance 
cellular uptake in vitro. The situation may be different in vivo due to the difference in the protein corona when we consider the YSK-MEND versus the R8/YSK-MEND. The R8/YSK-MEND showed a remarkably high spleen/liver ratio (>20) indicating that this system is a promising candidate as a new pDNA delivery system for targeting the spleen, although the exact mechanism of spleen targeting was unclear at this stage.

\section{Table 1.}

Composition and characterization of the different MENDs prepared by a 2-step coating

\begin{tabular}{lcccc}
\hline & Lipid Composition $^{\text {a) }}$ & Diameter $^{\text {b) }[\mathrm{nm}]}$ & PDI & Z-potential [mV] \\
\hline YSK-MEND (Y) & $\begin{array}{c}\text { First coat; DOPE } \\
\text { R8/YSK-MEND (RY) }\end{array}$ & $181.6 \pm 8$ & $0.314 \pm 0.07$ & $(-) 14.4 \pm 3.8$ \\
& $\begin{array}{c}\text { Second coat; YSK05/Chol/PEG (78.5/20/1.5) } \\
\text { First coat; DOPE/STR-R8 (97.75/2.25) } \\
\text { Second coat; YSK05/Chol/PEG (78.5/20/1.5) }\end{array}$ & $201.8 \pm 32$ & $0.340 \pm 0.05$ & $(-) 21.5 \pm 4.2$ \\
\hline
\end{tabular}

a) First coat/Second coat $\left.=1 / 1(\mathrm{nmol} / \mathrm{nmol}) ;{ }^{b}\right)$ Values are mean \pm SD of at least three different preparations

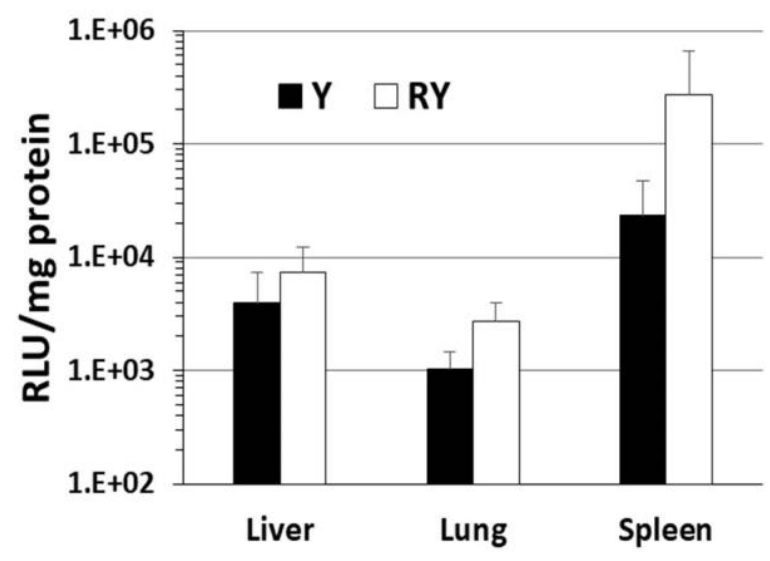

Figure 1. Comparison of gene expression of the YSK-MEND (Y) and the R8/YSK-MEND (RY) in different organs after IV injection to mice. Luciferase activities were measured at $6 \mathrm{hr}$ after injection and expressed as relative light units per $\mathrm{mg}$ of total proteins (RLU/mg protein). Each bar represents the mean +/-SD of at least 3 different experiments. 


\subsection{Optimization of R8/YSK-MEND}

Although the R8/YSK-MEND showed a high gene expression in the spleen, we concluded that the system could be further improved by in vivo optimization since the in vivo situation is much more complicated than in vitro conditions. The objective was to increase transfection activities in the spleen while maintaining the same high spleen/liver selectivity. We were also interested in identifying the factors that could affect liver and spleen selectivity. We optimized the R8/YSK-MEND with respect to the total amount of lipid used and lipid composition. The total amount of lipid and the ratios of YSK05, cholesterol, and DMG-PEG were changed and the luciferase activities in the spleen and liver were compared (Fig. 2 and Fig. S2). Characterization of the different NPs used in the optimization study is shown in Table S1. Decreasing the amount of total lipids resulted in a slightly increased activity in the spleen while it did not affect the spleen/liver ratio (Fig. 2a). In a previous study, we reported a similar improved gene expression in the liver by decreasing the total lipid amount [27]. The lower amount of lipid may aid in the ease of removing the outer lipid at the time of endosomal escape and may facilitate the decondensation and release of DNA from the carriers. Because the encapsulation efficiency of the pDNA was low at $160 \mathrm{nmol}$ of lipid ( 30\%), the R8/YSK-MEND prepared with $320 \mathrm{nmol}$ lipid was used in further optimization experiments (EE is $\sim 63 \%$ ).

The amount of YSK05 in the outer lipid layer affected gene expression in the spleen. The inclusion of YSK05 enhances endosomal escape and this would be expected to increase transfection efficiency [34]. However, we found that when using YSK05 as 40 mol\% and DOPE at $50 \mathrm{~mol} \%$, this combination showed the highest gene expression in the spleen (Fig. 2b). The decrease in activity at $30 \mathrm{~mol} \%$ YSK05 can be attributed to a decrease in endosomal escape efficiency. Meanwhile, the decrease in activity when a higher YSK05 amount (50 or 60 mol\%) is 
used is assumed to result from the lower amount of DOPE used as an inner lipid. We hypothesize that using low amounts of DOPE as an inner lipid did not cause efficient DNA encapsulation and allowed more free pDNA to exist after the first coating. This free pDNA would be coated only by the second coat, which may reduce overall activity. In contrast, when a sufficient amount of DOPE is used in the inner coat, most of the pDNA will be coated with the first coat and subsequently more double coated nanoparticles will be available after the second coating. This explains the importance of the amount of DOPE used in the first coating. It appears that a need exists for a compromised condition which allows both good encapsulation in double-coated NPs and an acceptable level of endosomal escape. The amount of cholesterol in the outer lipid also affected the level of gene expression as evidenced by the finding that the system prepared with $15 \mathrm{~mol} \%$ cholesterol showed the highest spleen activity and highest spleen/liver ratio (Fig. 2c and Fig. S2). In general, increasing the amount of cholesterol stabilizes the lipid membrane structure of the liposome, resulting in a more rigid structure [35]. An optimum amount of cholesterol appears to be important for stabilizing the system in the circulation, although higher levels of cholesterol may impair transfection in different ways. It has been reported that cholesterol-rich liposomes were readily taken up by splenic phagocytic cells [36], and this may lead to more degradation of the system. Many complement components (such as C3 proteins) bind to liposomes with a high amount of cholesterol and such systems are thought to be taken up by macrophages [37]. A higher level of cholesterol may also impair endosomal escape or the decondensation of pDNA. Finally, the effect of the amount of DMG-PEG on transfection activities was investigated. The activity of the original system (PEG $0.75 \mathrm{~mol} \%$ of the total lipid) was higher than the $2.5 \mathrm{~mol} \%$ PEG and was close to the $1.5 \mathrm{~mol} \%$ PEG (Fig. 2d). However, the ratio of luciferase activity in the spleen to that in the liver was higher when $1.5 \mathrm{~mol} \%$ PEG was 
used compared to when $0.75 \mathrm{~mol} \%$ PEG was used (Fig. S2), indicating that $1.5 \mathrm{~mol} \%$ PEG results in more spleen specificity. PEG-lipids are typically incorporated into lipid-based systems to produce a hydrophilic steric barrier that inhibits binding to plasma proteins, including opsonins, which mark NPs for removal by the mononuclear phagocytic system [38]. However, the fatty acid chain of the DMG-PEG contains 14 carbon atoms and the interaction with the NP lipid membrane is weak, causing DMG-PEG to rapidly become desorbed from NPs in the circulation [39]. Therefore, DMG-PEG is mainly used to control particle size and to prevent aggregation during the preparation of lipid NPs. However, a higher amount of DMG-PEG (2.5 mol\% of total lipid) may not be fully desorbed in the circulation and the remaining PEG could impair cellular uptake and endosomal escape [40]. In addition, the detaching of numerous DMGPEG molecules from the MEND surface may cause destabilization of the system. The exact reason for the improvement in spleen selectivity when $1.5 \mathrm{~mol} \%$ DMG-PEG is used is not clear. It is thought that the amount of PEG remaining on the surface might be higher when using 1.5 mol\% which might inhibit the migration to hepatocytes via ApoE-mediated endocytosis [41]. Based on these results, the optimal composition for in vivo spleen transfection was determined as shown in Table S2. The optimization steps resulted in an increase of more than 5 fold in the level of gene expression in the spleen, reaching more than $10^{6} \mathrm{RLU} / \mathrm{mg}$ of protein and the spleen/liver ratio of transfection activities remained still high $(\sim 20)$. We were not able to identify a higher value for spleen gene expression and selectivity of pDNA delivery systems in the literature $[19,20]$. The gene expression of the optimized system showed a peak at 6 hours post injection (Fig. S3a). Different biological and immunological processes in the body may limit gene expression after longer times or cause the produced gene to undergo degradation. Measuring different markers of toxicities in the serum of mice treated with the optimized 
R8/YSK-MEND revealed no signs of acute toxicities compared to the PBS-treated mice (Fig.

7a).
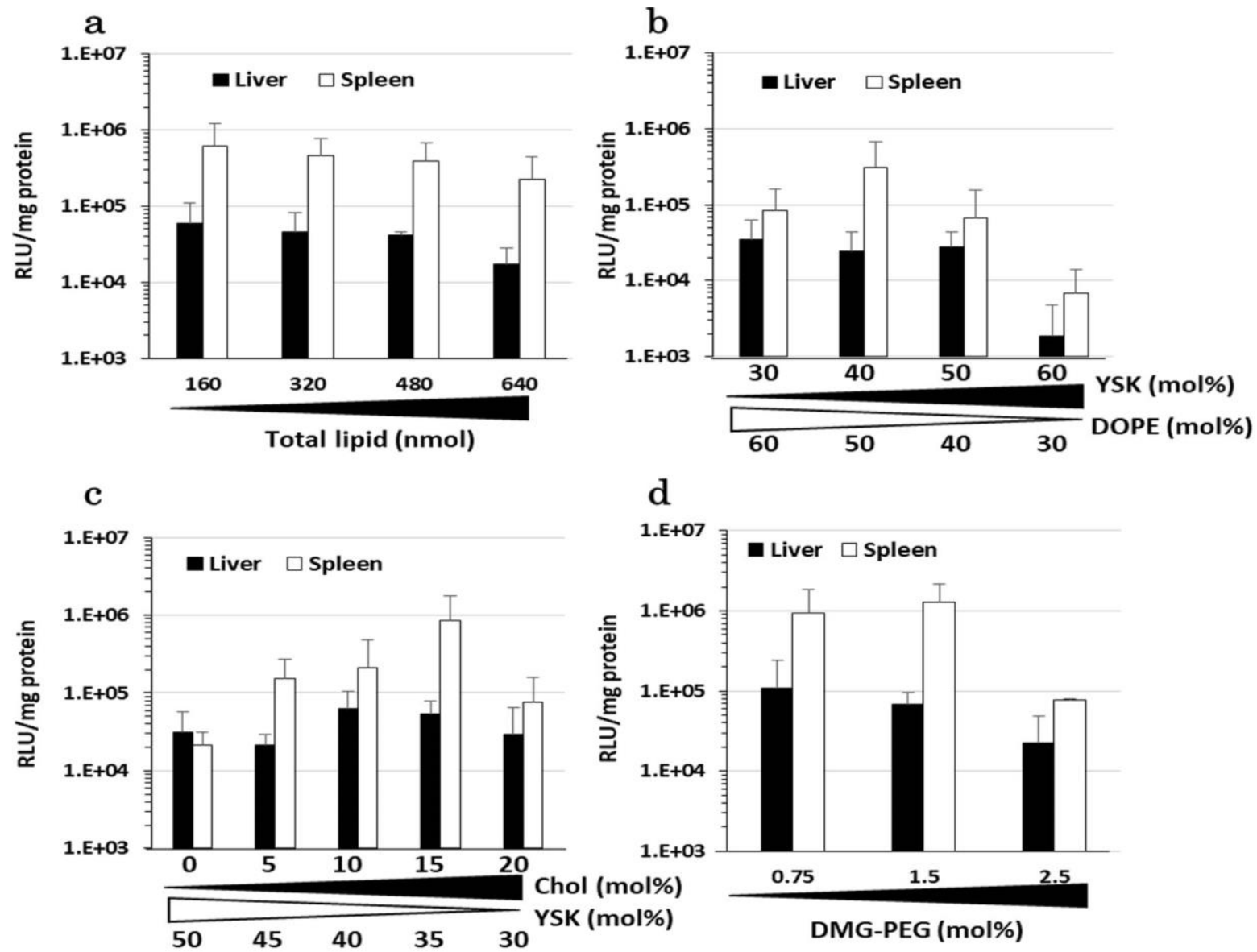

d

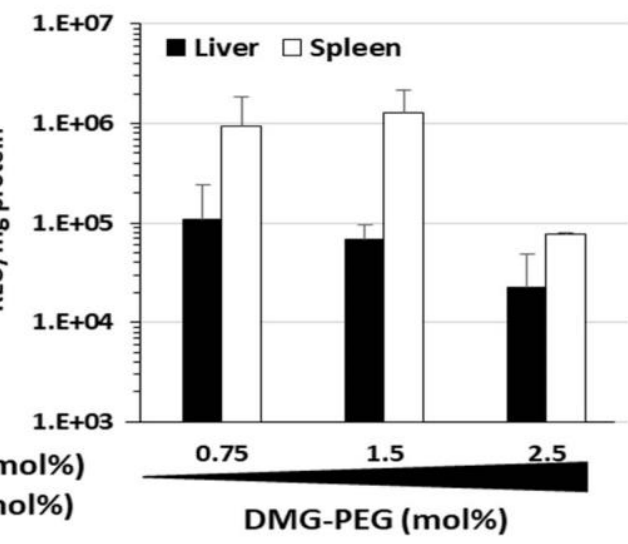

Figure 2. Optimization of the lipid composition of the R8/YSK-MENDs. Mice were treated with different MENDs prepared with different amounts of lipid and lipid compositions. Luciferase activities in the liver and spleen were measured at $6 \mathrm{hr}$ after injection and are expressed as relative light units per $\mathrm{mg}$ of total proteins (RLU/mg protein). Different lipid components are expressed as mol\% of total lipids. Each bar represents the mean $+/-$ SD of at least 3 different experiments.

\subsection{Conventional 1-step coating vs. 2-step coating}

We previously reported on a 2-step coating strategy as a new method for preparing a MEND system and confirmed that the 2-step coating showed a more efficient gene expression compared to the conventional 1-step coating in in vitro experiments [32]. To evaluate the value of the 2-step coating design in vivo, we compared the luciferase activities and the biodistribution of the optimized R8/YSK-MENDs prepared using the conventional 1-step coating or the 2-step 
coating. The same amount of lipid and composition were used when comparing the 1-step versus 2-step coating so that the only difference was in the method used in the preparation. Data concerning the lipid composition and the characterization of the different MENDs are shown in Table 2. As shown in Fig. 3a, the R8/YSK-MEND prepared by the 2-step coating procedure caused a higher gene expression compared to the 1-step coating in all organs, especially in the spleen ( 13 -fold). This is consistent with the previous in vitro study, which showed the superiority of double-coated MEND at the cellular level. Both MENDs were similarly delivered to the liver or lung, however, higher levels of the MEND prepared with the 2-step coating were taken up by the spleen compared to the 1-step coating MEND (Fig. 3b). More rigid particles tend to be trapped in the spleen more frequently [8]. The MEND prepared with a 2-step coating is probably more rigid than that prepared with 1-step coating. In addition, the encapsulation of DNA in the inner coat may leave the YSK05 outer layer more free (not bound to DNA) which may affect the ability of the system to bind to endogenous proteins and reach spleen cells. Although the higher gene expression in the spleen may be explained by a higher delivery to an organ per gram of tissue, this is not the only reason as evidenced by calculating the gene expression efficiency in different organs by dividing the luciferase activity by the amount of pDNA delivered in each case (Fig. 3c). In both MENDs (1- or 2-step coating), the efficiency of gene expression was higher in the spleen compared to the liver or lung. The diameter of the NPs used was $>150 \mathrm{~nm}$, which means that a large fraction of the NPs may not be able to pass the liver fenestrae and may be entrapped by liver macrophages (Kupffer cells) and liver sinusoidal endothelial cells (LSECs) with subsequent degradation. Thus, the low delivery to hepatocytes may be responsible for the decreased transfection efficiency in the case of the liver. Meanwhile, the spleen is characterized by the presence of both open and closed circulation and the particles 
distributed to the spleen would probably be taken up by non-phagocytic cells, which are more easily transfected compared to macrophages. It is note worthy that the efficiency of the 2-step coated preparation was dramatically high in the spleen compared to other organs $(\sim 15$ fold $)$, indicating that the optimized double coated system has a selective spleen enhanced transfection activity. Although the exact reason for this enhanced spleen-selective transfection is not known, we hypothesize that the double coated design may affect the interactions with the protein corona. As shown in Fig. S4c, the nanoparticles are coated with serum components when they are incubated in serum, which may be relevant to delivery to the spleen and the selective efficiency for this organ. Although the size may affect the distribution to different liver and spleen cells and the uptake into spleen cells is higher for double-coated carriers, the enhanced expression efficiency is the main reason for the enhanced spleen transfection. Collectively, these results confirm the advantage of a 2-step coating in gene expression and spleen specificity in vivo.

\section{Table 2}

Composition and characterization of different MENDs prepared by a 1-step or a 2-step coating

\begin{tabular}{lcccc}
\hline & Lipid Composition ${ }^{\mathrm{a})}$ & Diameter $^{\mathrm{b})}[\mathrm{nm}]$ & PDI & Z-potential [mV] \\
\hline 1-step coating & $\begin{array}{c}\text { DOPE/STR-R8/YSK05/Chol/PEG } \\
(47.75 / 2.25 / 34.25 / 14.25 / 1.5)\end{array}$ & $216.7 \pm 36.1$ & $0.374 \pm 0.030$ & $(-) 12.5 \pm 4.5$ \\
2-step coating & $\begin{array}{c}\text { First coat; DOPE/STR-R8 (95.5/4.5) } \\
\text { Second coat; YSK05/Chol/PEG (68.5/28.5/3) }\end{array}$ & $155.9 \pm 18.0$ & $0.251 \pm 0.066$ & $(-) 14.2 \pm 13.9$ \\
\hline
\end{tabular}

\footnotetext{
${ }^{\mathrm{a})}$ First coat/Second coat $\left.=1 / 1(\mathrm{nmol} / \mathrm{nmol}) ;{ }^{\mathrm{b}}\right)$ Values are mean \pm SD of at least three different preparations
} 

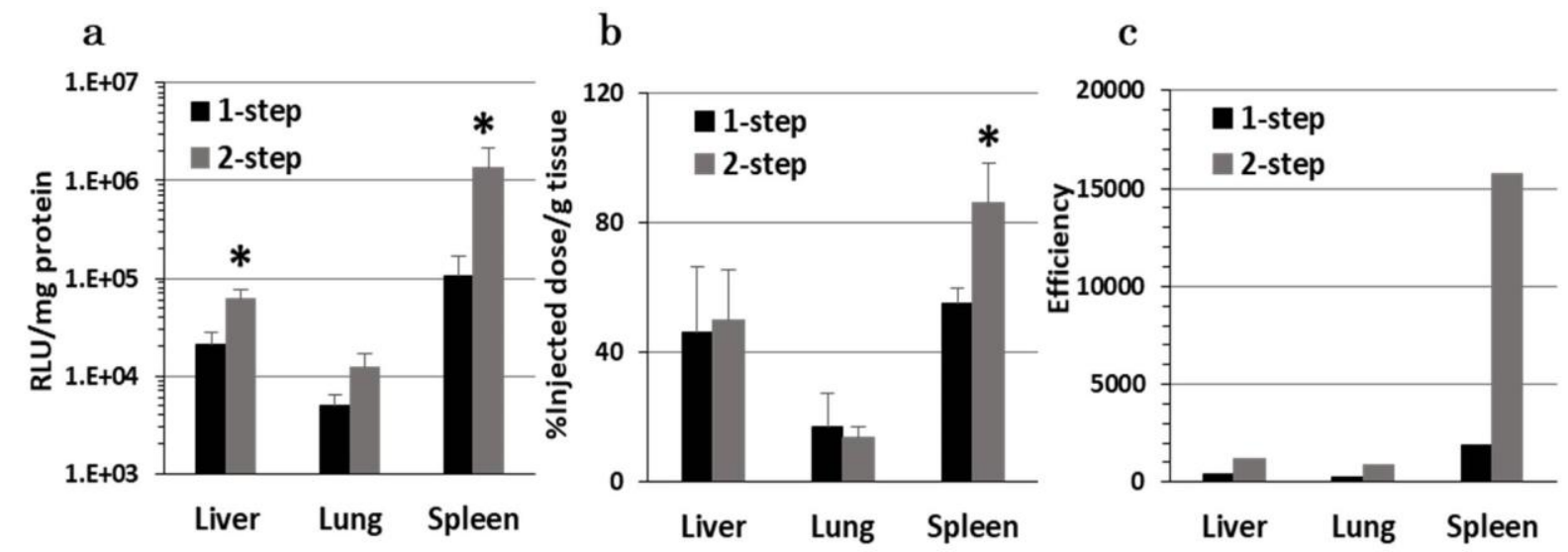

Figure 3. Comparison of MENDs prepared by 1-step or 2-step coating in vivo.

Mice were treated with different MENDs prepared by 1-step or 2-step coating. (a) Luciferase activity in different organs, (b) Biodistribution of different MENDs expressed as the percent of the dose per gram of tissue. Each bar represents the mean +/-SD of at least 3 different experiments ( ${ }^{*} p<0.05$ vs. $1 \mathrm{~s}$ ). (c) Gene expression efficiency was calculated by dividing luciferase activity by the dose of MEND delivered per gram of tissue.

\subsection{Synergism between R8 and YSK05}

We previously confirmed that R8 and YSK05 function synergistically in transfection activities in vitro [32]. To investigate the synergistic effect of this combination in the case of in vivo gene expression, we compared the luciferase activities of the MENDs prepared with YSK05 or a conventional cationic lipid (DOTAP) in the presence or absence of R8. In the absence of YSK05, the inclusion of a conventional cationic lipid was essential since a positive component is needed for efficient lipid coating of DNA. The 1-step coating (1s) was used in the absence of R8 while the 2-step coating (2s) was used in the presence of R8 (Fig. 4a). The lipid composition and characterization of the different MENDs are shown in Table 3. As shown in Fig. 4b, the transfection activities of all of the MENDs were higher in the spleen compared to the liver or lung. However, the highest activity in all three organs was observed when R8 was combined with YSK05 in a double-coating design (RY2s). This confirms the synergistic effect of R8 and YSK05 in gene expression in vivo, particularly in the spleen. To understand the factors affecting 
the difference in gene expression in each case, we performed a biodistribution study and calculated the efficiency of gene expression in different organs. The optimized double coated R8/YSK-MEND (RY2s) showed the highest spleen accumulation (Fig. 4c), and also the highest gene expression efficiency in the spleen (Fig. 4d). DOTAP-MENDs (with or without R8) showed a low efficiency of gene expression in all three organs while the YSK-MEND (Y1s) showed a higher gene expression efficiency in the spleen. Consistent with the results shown in Fig. 3, the optimized RY2s-MEND showed the highest efficiency in the spleen. The data shown in Fig. 4 indicate that this selective spleen enhanced transfection activity is driven by synergism between R8 and YSK05. A size effect would not be expected in this case as equal doses were delivered to the liver in all cases and only a small difference was observed in the doses delivered to the spleen (Fig. 4c). As discussed before, the higher degradation in liver macrophages and endothelial cells is one factor for explaining the low gene expression efficiency of the R8/YSKMEND (RY2s) in the liver. It has been reported that there is a large difference in transfection efficiency among different cell lines due to differences in degradation activities [42-45]. In addition, the protein corona coating may be different between the DOTAP or YSK systems and this difference may affect the uptake pathway and intracellular trafficking. The optimized R8YSK-MEND appears to be taken up through a pathway that favors the gene expression more than other cases. Thus, the difference among organs is thought to be due, not only to a difference in biodistribution but also to a difference in transfection efficiency of cells in different organs. 
Table 3 Composition and characterization of the different MENDs prepared with or without YSK05 or R8

\begin{tabular}{|c|c|c|c|c|}
\hline & Lipid Composition & $\begin{array}{l}\text { Diameter } \\
\quad(\mathrm{nm})\end{array}$ & PDI & $\begin{array}{l}\text { Z-potential } \\
(\mathrm{mV})\end{array}$ \\
\hline $\begin{array}{l}\text { DOTAP-MEND } \\
\text { (1-step coating) (D1s) }\end{array}$ & $\begin{array}{l}\text { DOPE/DOTAP/Chol/PEG } \\
(50 / 34.25 / 14.25 / 1.5)\end{array}$ & $164.7 \pm 25.6$ & $0.284 \pm 0.098$ & (-) $12.4 \pm 7.9$ \\
\hline $\begin{array}{l}\text { YSK-MEND } \\
\text { (1-step coating) (Y1s) }\end{array}$ & DOPE/YSK05/Chol/PEG (50/34.25/14.25/1.5) & $212.8 \pm 54.0$ & $0.373 \pm 0.068$ & (-) $16.8 \pm 5.8$ \\
\hline $\begin{array}{l}\text { R8/DOTAP-MEND } \\
\text { (2-step coating) (RD2s) }\end{array}$ & $\begin{array}{c}\text { First coat; DOPE/STR-R8 }(95.5 / 4.5) \\
\text { Second coat; DOTAP/Chol/PEG }(68.5 / 28.5 / 3)\end{array}$ & $157.3 \pm 10.7$ & $0.262 \pm 0.040$ & (-) $19.9 \pm 3.8$ \\
\hline $\begin{array}{l}\text { R8/YSK-MEND } \\
\text { (2-step coating) (RY2s) }\end{array}$ & $\begin{array}{c}\text { First coat; DOPE/STR-R8 }(95.5 / 4.5) \\
\text { Second coat; YSK05/Chol/PEG }(68.5 / 28.5 / 3)\end{array}$ & $162.3 \pm 14.9$ & $0.232 \pm 0.027$ & (-) $16.8 \pm 5.9$ \\
\hline
\end{tabular}

\footnotetext{
${ }^{\mathrm{a})}$ First coat/Second coat $=1 / 1(\mathrm{nmol} / \mathrm{nmol}) ;{ }^{\mathrm{b}}$ Values are mean \pm SD of at least three different preparations
}

a

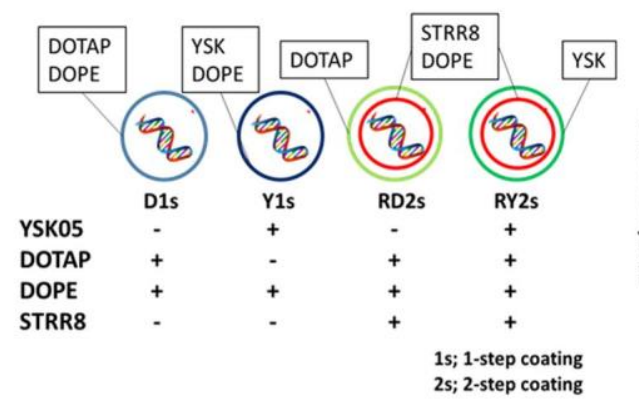

c

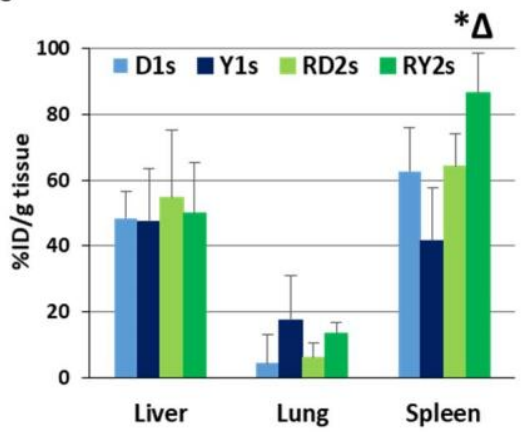

$\mathrm{b}$

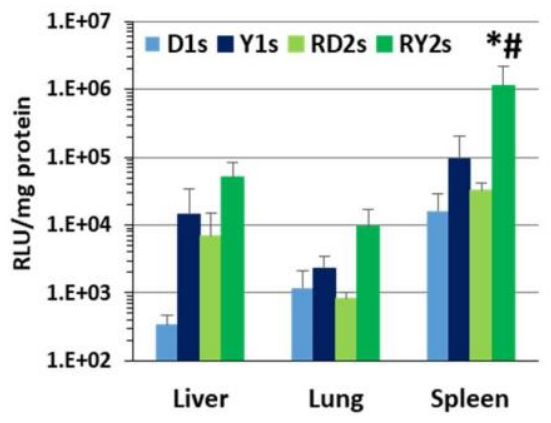

d

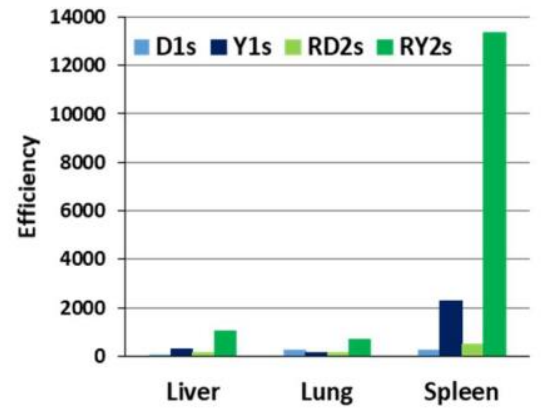

Figure 4. Comparison of different MENDs prepared in the presence or absence of R8 or YSK05. (a) Schematic representation of the different forms of MENDs used. (b) Luciferase activities in different organs at $6 \mathrm{hr}$ after IV injection (expressed as RLU/mg protein). Each bar represents the mean +/-SD of at least 3 different experiments ( ${ }^{*} \mathrm{p}<0.05$ vs. RY2s (liver) and Y1s, RD2s (spleen), ${ }^{*} \mathrm{P}<0.01 \mathrm{vs}$. D1s, Y1s, RD2s (liver), D1s, Y1s, RD2s, RY2s (lung), and D1s (spleen)). (c) Biodistribution of different MENDs (expressed as \%ID/g tissue). Each bar represents the mean +/-SD of at least 3 different experiments (*p<0.05 vs. D1s, Y1s, RD2s, RY2s (lung), ${ }^{\Delta} \mathrm{P}<0.01$ vs. Y1s (spleen)). (d) Gene expression efficiency was calculated by dividing luciferase activity by the dose of MEND delivered per gram of tissue. 


\subsection{Determination of which spleen cells are taking up the MEND system}

To clarify the reason for the high efficiency of gene expression in the spleen in the case of the optimized double coated R8/YSK-MEND, we examined the issue of which specific cells in the spleen are taking up the system. Identifying the transfected cells is also important for selecting the appropriate therapeutic application of the system. The spleen is a reticulo-lymphoid organ that is extensively involved in various immunological functions of the body. Anatomically, it can be divided into three zones: red pulp, white pulp and marginal zone $[8,46]$. We used specific antibodies to identify the most important immune cells in the spleen (B cells, T cells, dendritic cells (DCs) and macrophages). Most of the detected spleen cells are B cells or T cells while DCs and macrophages represent a much lower percentage of the total cells detected (Fig. S5). The R8/YSK-MEND was mainly distributed to antigen presenting cells (APCs) such as macrophages, DCs and B cells. However, most of the fluorescence was localized in B cells ( 90\%) (Fig. 5), indicating that most of the dose was successfully delivered to B cells in the spleen. When comparing the percentage of cells that received particles, most of the macrophages ( $\sim 80 \%)$ were positive compared to $\sim 50 \%$ of B cells and lower percentages of DCs and T cells (Fig. 5c). We also examined the distribution of the R8/YSK-MEND in the spleen by confocal microscopy. As shown in Fig. S6, the R8/YSK-MEND is highly colocalized with macrophages and partially localized with B cells. This result is consistent with the results of flow cytometry, which confirms the ability of the system to reach macrophages and B cells, in particular. Transfecting a significant proportion of B cells indicates that the system can pass through fenestrations in the white pulp in the spleen. This may explain the selective enhancement of spleen efficiency since transfecting cells other than macrophages and DCs may be easier [47]. The B cells are not only antibodies producing cells, but they are also active as APCs [9, 
48].Therefore, the R8/YSK-MEND is efficiently delivered to different APCs, which makes it a promising candidate for therapeutic applications to DNA vaccines.

Shen et. al. reported that the protein corona is responsible for the targeting of nanocarriers to B cells in the spleen. We examined the optimized R8/YSK-MEND by electron microscopy after incubation with mouse serum. A representative TEM image of the NPs after incubation with serum is shown in Fig. S4c. The nanoparticles preserved their spherical structure after incubation with serum. However, a significant difference in electron density was observed after the incubation, which indicates that serum proteins are located on the surface of the particles. While most of the nanoparticles appeared as single units after a short period of incubation with serum ( $5 \mathrm{~min}$ ), we observed that some of the nanoparticles were bound to each other to form aggregates of two nanoparticles. We hypothesize that a prolonged incubation with serum causes more nanoparticles to aggregate, which appeared as a separate peaks in the histograms in Fig. S4. This is consistent with the model proposed by Corbo et. al. for describing the protein corona and liposome interaction [49].

We also investigated the physicochemical properties of the optimized MEND incubated with serum (Fig. S4 a-b). The size and the PDI of nanoparticles tend to increase with increasing incubation time. A separate peak indicating the presence of aggregated nanoparticles appeared and increased with time (from 5 to $30 \mathrm{~min}$ ). Furthermore, the surface charge decreased as soon as the MEND was incubated with serum. This confirms our previous conclusion that the nanoparticles become coated with serum components and some of them start to bind to each other to form aggregates of two, which continue to grow to form larger aggregates on further incubation (Fig. S4c). The interaction with the protein corona appears to play a critical role in 
targeting the MEND system to different spleen cells. More detailed studies will be needed to clarify this role.

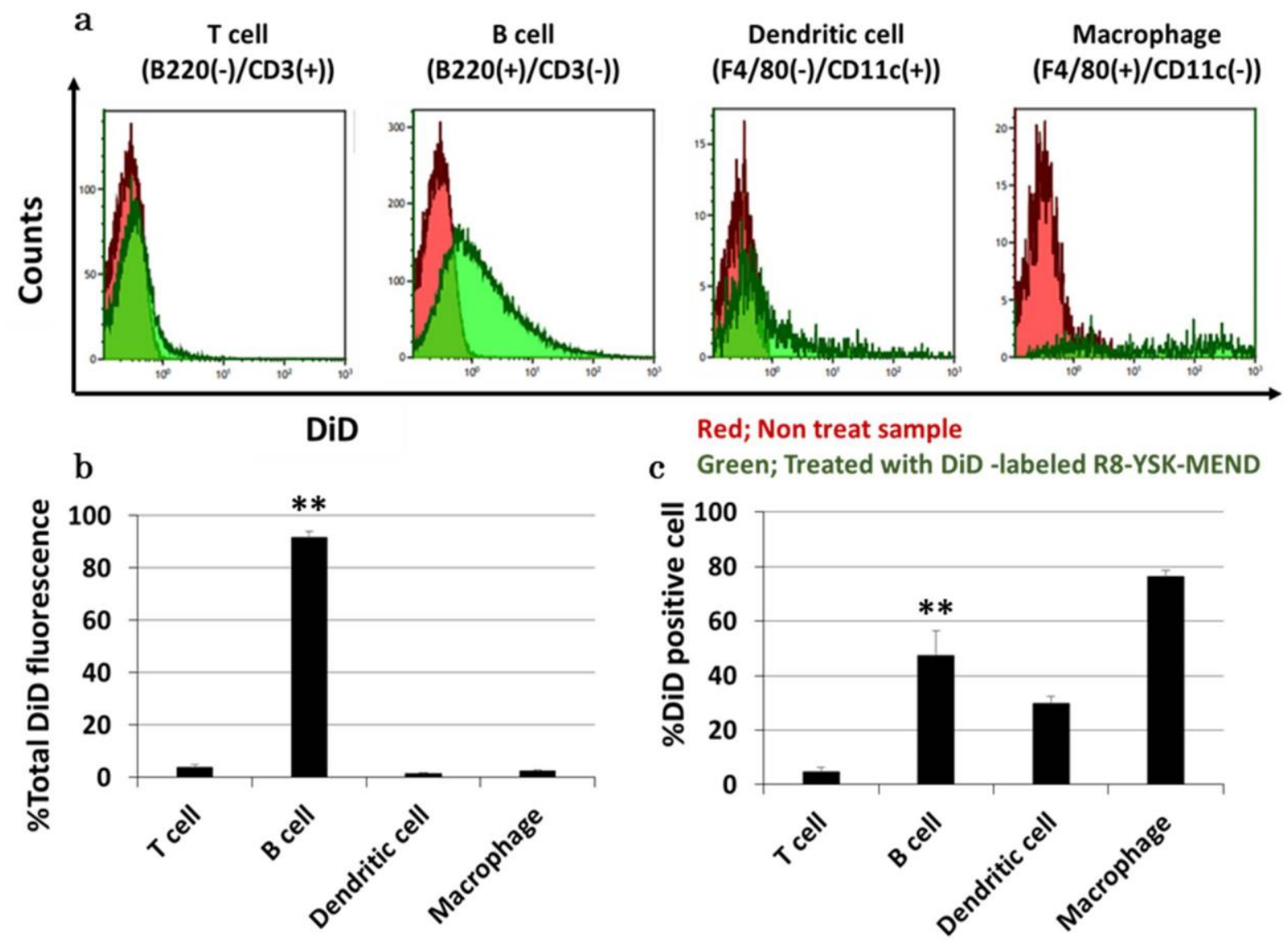

Figure 5. Spleen cell type taking up the R8/YSK-MEND system. At $6 \mathrm{hr}$ after the injection of the DiD labeled R8/YSK-MEND, mouse spleens were dissected and dispersed into single cells. The splenocytes were stained with several antibodies and then analyzed by flow cytometry (a). The total fluorescence (b) as well as the percent positive cells (c) were determined in each case. Each bar represents the mean +/- SD of 3 different experiments $(* * \mathrm{P}<0.01$ vs. T cells, DCs and macrophages).

\subsection{R8/YSK-MEND as a DNA vaccine for suppressing tumor growth}

To test the applicability of the system as a DNA vaccine, we evaluated the therapeutic effect of the R8/YSK-MEND as a DNA vaccine for suppressing tumor growth. In this study, mice were treated with PBS, a naked antigen (OVA)-coding pDNA (naked pOVA), the optimized R8/YSKMEND encapsulating luciferase-coding pDNA (RY pLuc), or encapsulating an antigen (OVA)- 
coding pDNA (RY pOVA) at 1 and 2 weeks before tumor inoculation. After inoculating E.G7OVA cells, tumor volume was monitored over a period of 30 days (Fig. 6a). Tumor volumes in the RY pLuc-treated mice were comparable to those in the PBS-treated mice. However, a strong antitumor effect was observed in the case of naked pOVA and RY pOVA. The RY pOVA completely inhibited tumor growth without the need for an additional adjuvant. We were not able to detect any tumor growth in all of the 6 mice that received the RY pOVA vaccine for up to 30 days after tumor inoculation. This indicates that the RY pOVA successfully delivered and expressed the antigen pDNA in APCs, which induced a high antigen-specific anti-tumor activity. The system showed a strong anti-tumor activity even without the need for an additional adjuvant. This is advantageous since adjuvants can induce undesirable inflammatory reactions [50]. DNA can itself function as an adjuvant to trigger cellular immunity. Therefore, the R8/YSK system encapsulating OVA-encoded DNA has the potential for both expressing specific antigens and activating the immune system as an adjuvant. Naked antigenic pDNA also showed a significant anti-tumor effect, although the efficiency of tumor suppression was stronger in the case of the RY pOVA. This result confirms that the R8/YSK-MEND is a potent vector for cancer immunization and has great promise for applications in the field of DNA vaccination in the future. We also attempted to evaluate the efficacy of the original composition (YSK-MEND, shown in Fig. 1). However, the original lipid composition showed signs of toxicity during the prophylactic study. The original composition has twice the amount of lipid per pDNA and has a higher cationic lipid ratio compared to the optimized composition, which may explain the toxicity and confirm the advantage of the optimized formulation.

We then examined the anti-tumor effect of the optimized system in mice with existing tumors. Mice were injected with PBS, naked pOVA or the R8/YSK-MEND encapsulating OVA- 
coding pDNA at 7, 10, 14 days after tumor inoculation. The optimized R8/YSK-MEND encapsulating luciferase-coding pDNA (RY pLuc) was not included in this study since we found no prophylactic antitumor effect when these particles were used. There were no significant differences in tumor growth in mice treated with PBS or naked pOVA. However, a slower tumor growth was observed in mice that had been treated with RY pOVA (Fig. 6b). The tumor size was significantly lower at 16, 20, and 24 days after tumor inoculation between PBS/naked pOVA and RY pOVA. These results indicate that the R8/YSK-MEND can be used for the treatment of existing tumors, although the prophylactic effect was more evidenced (Fig. 6a). Interestingly, the use of naked pOVA produced a significant prophylactic effect, while it did not show a significant therapeutic effect on existing tumors. This indicates that only the stimulation of innate immunity is not sufficient to cure existing tumors. It is likely that both the activation of immune cells and antigen-presentation are necessary in order to produce a significant therapeutic effect on existing tumors. The injection of naked $\mathrm{CpG}$ containing luciferase pDNA failed to produce a significant gene expression in the spleen (Fig. S3b), indicating that the stimulation of innate immunity does not require successful gene expression. In contrast, a significant expression of the antigen appears to be required for achieving an antitumor effect in the case of existing tumors. 

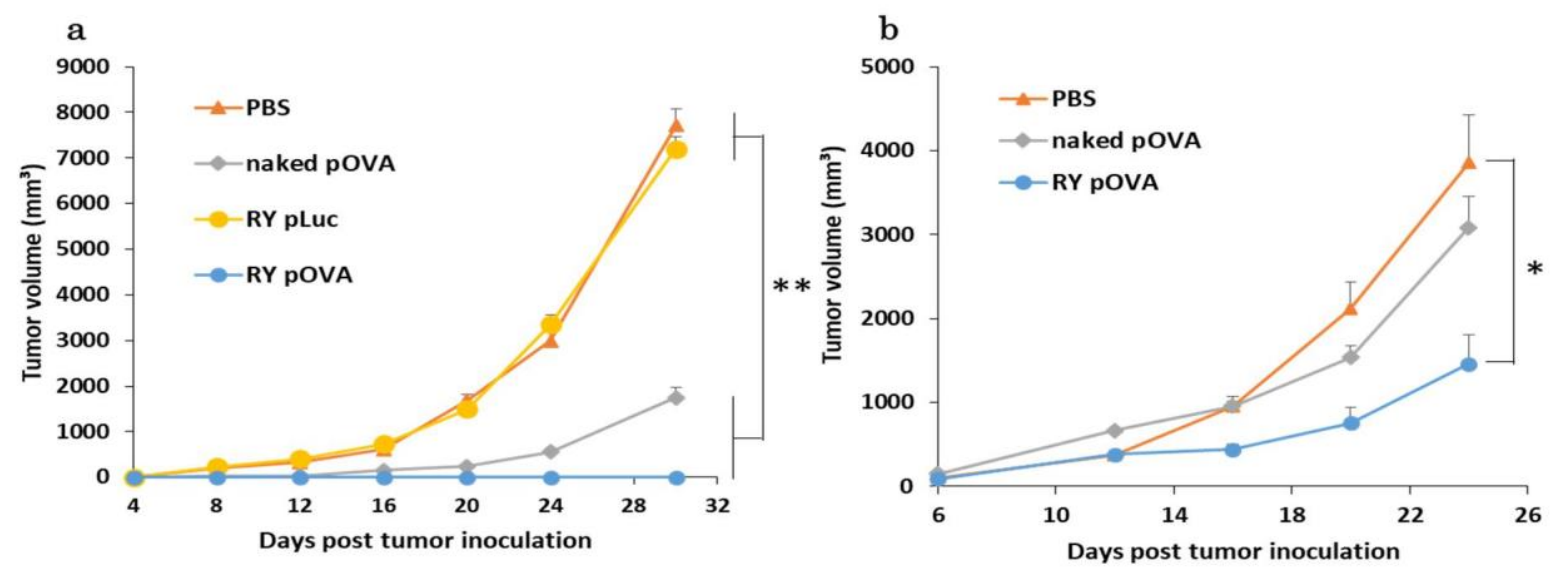

Figure 6. In vivo anti-tumor effect of R8/YSK-MEND encapsulating antigen (OVA)-coding pDNA. (a) Prophylactic effect: C57BL/6 mice were injected twice with the R8/YSK-MEND encapsulating OVA-coding pDNA (RY OVA) on 7 and 14 days before tumor inoculation. The mice were inoculated with E.G7-OVA cells and the tumor volume was monitored. Mice groups treated with PBS, naked OVA-coding pDNA (naked pOVA), and R8/YSK-MEND encapsulating luciferase-coding pDNA (RY Luc) were used as different controls. (b) Therapeutic effect: C57BL/6 mice were inoculated with E.G7-OVA cells and different samples were injected at 7, 10 and 14 days after tumor inoculation. The plots represent the mean +/-SD (a total of 6 mice/group) ( $\left.{ }^{*} \mathrm{P}<0.05,{ }^{* *} \mathrm{P}<0.01\right)$.

We also examined the prophylactic effect of DOTAP nanoparticles to confirm the value of synergism between YSK05 and R8. Similar to PBS treatment, the DOTAP nanoparticles showed no significant prophylactic effect (Fig. S7). This confirms that synergism between YSK05 and R8 leading to a high level of transfection in spleen cells is critical for achieving an anti-tumor effect. It should be noted that the levels of Interleukin 6 (IL-6) were significantly higher in the case of mice injected with the optimized MEND encapsulating OVA-pDNA compared to mice injected with naked OVA-pDNA (Fig. 7b). This indicates that a MEND encapsulating OVApDNA produced a significantly higher level of immune stimulation. The MEND encapsulating the CpG-containing Luc-pDNA also produced significantly higher IL-6 levels compared to control mice, although no prophylactic anti-tumor effect was found. This indicates that the immune stimulation of non-specific pDNA is not sufficient to produce a significant anti-tumor effect. 

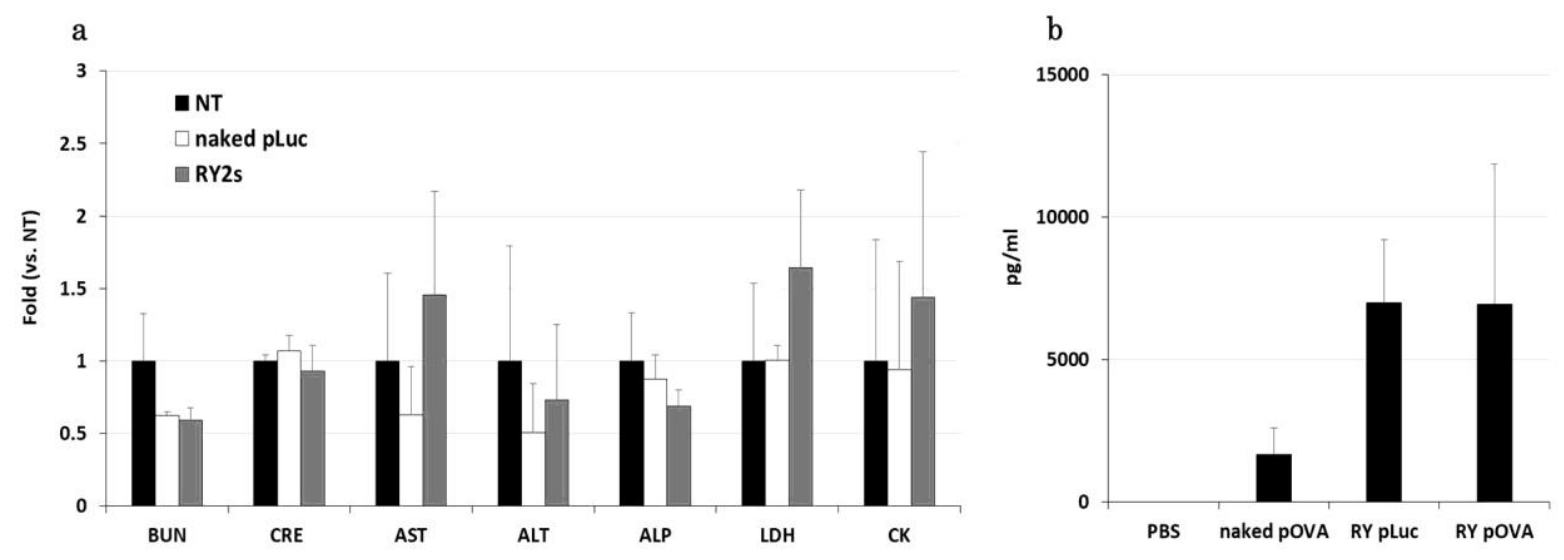

Figure 7. In vivo toxicity and immune stimulation of R8/YSK-MEND.

(a) In vivo toxicity: ICR mice were injected with naked Luc pDNA or pDNA encapsulated in R8/YSKMEND. Different biomarkers were measured in the serum $6 \mathrm{hr}$ after injection (neutralized to mice treated with PBS). Each column represents the mean +/-SD (n=3). (b) Measurement of IL-6 levels in the serum $1 \mathrm{hr}$ after injection of PBS, naked pOVA, or R8/YSK-MEND encapsulating pLuc or pOVA. Each column represents the mean +/-SD ( $n=3)$. BUN: Blood urea nitrogen; CRE: Creatinine; AST: Aspartate aminotransferase; ALT: Alanine aminotransferase; ALP: Alkaline phosphatase; LDH: Lactate dehydrogenase; CK: Creatine kinase. 


\section{Conclusion}

In summary, we report herein on the development of an efficient spleen-targeted gene delivery system based on synergism between a cell-penetrating peptide (R8 peptide) and a pHresponsive ionizable lipid (YSK05). The difference in gene expression among organs could not be explained based on the biodistribution of the carriers where the efficiency of gene expression in spleen cells is dramatically higher than cells in other organs. The R8/YSK-MEND developed in this study holds great promise as an efficient spleen-targeted pDNA delivery system for future applications in the field of DNA vaccinations. 


\section{Conflict of interest}

The authors declare no competing financial interest. 


\section{ACKNOWLEDGMENT}

This work was supported by the Special Education and Research Expenses from the Ministry of

Education, Culture, Sports, Science and Technology (MEXT) - Japan. We thank Dr. Milton

Feather for his helpful advice in editing English in this manuscript. 


\section{REFERENCES}

[1] M. Collins, A. Thrasher, Gene therapy: progress and predictions, Proc Biol Sci, 282 (2015) 20143003.

[2] K.B. Kaufmann, H. Büning, A. Galy, A. Schambach, M. Grez, Gene therapy on the move, EMBO Mol Med, 5 (2013) 1642-1661.

[3] A. Mountain, Gene therapy: the first decade, Trends Biotechnol, 18 (2000) 119-128.

[4] H. Yin, R.L. Kanasty, A.A. Eltoukhy, A.J. Vegas, J.R. Dorkin, D.G. Anderson, Non-viral vectors for gene-based therapy, Nat Rev Genet, 15 (2014) 541-555.

[5] M. Elsabahy, A. Nazarali, M. Foldvari, Non-viral nucleic acid delivery: key challenges and future directions, Curr Drug Deliv, 8 (2011) 235-244.

[6] F. Alexis, E. Pridgen, L.K. Molnar, O.C. Farokhzad, Factors affecting the clearance and biodistribution of polymeric nanoparticles, Mol Pharm, 5 (2008) 505-515.

[7] I.A. Khalil, K. Kogure, H. Akita, H. Harashima, Uptake pathways and subsequent intracellular trafficking in nonviral gene delivery, Pharmacol Rev, 58 (2006) 32-45.

[8] A.B. Jindal, Nanocarriers for spleen targeting: anatomo-physiological considerations, formulation strategies and therapeutic potential, Drug Deliv Transl Res, 6 (2016) 473-485.

[9] L. Shen, S. Tenzer, W. Storck, D. Hobernik, V.K. Raker, K. Fischer, S. Decker, A. Dzionek, S. Krauthäuser, M. Diken, A. Nikolaev, J. Maxeiner, P. Schuster, C. Kappel, A. Verschoor, H. Schild, S. Grabbe, M. Bros, Protein corona-mediated targeting of nanocarriers to B cells allows redirection of allergic immune responses, J Allergy Clin Immunol, (2018).

[10] J.L. Schultze, S. Grabbe, M.S. von Bergwelt-Baildon, DCs and CD40-activated B cells: current and future avenues to cellular cancer immunotherapy, Trends in immunology, 25 (2004) 659-664.

[11] J.O. Jin, H. Park, W. Zhang, J.W. de Vries, A. Gruszka, M.W. Lee, D.R. Ahn, A. Herrmann, M. Kwak, Modular delivery of CpG-incorporated lipid-DNA nanoparticles for spleen DC activation, Biomaterials, 115 (2017) 81-89.

[12] R.A.M. Rossetti, N.P.C. Lorenzi, K. Yokochi, M. Rosa, L. Benevides, P.F.R. Margarido, E.C. Baracat, J.P. Carvalho, L.L. Villa, A.P. Lepique, B lymphocytes can be activated to act as antigen presenting cells to promote anti-tumor responses, PloS one, 13 (2018) e0199034.

[13] V.T. Colluru, D.G. McNeel, B lymphocytes as direct antigen-presenting cells for anti-tumor DNA vaccines, Oncotarget, 7 (2016) 67901-67918. 
[14] O.S. Fenton, K.J. Kauffman, J.C. Kaczmarek, R.L. McClellan, S. Jhunjhunwala, M.W. Tibbitt, M.D. Zeng, E.A. Appel, J.R. Dorkin, F.F. Mir, J.H. Yang, M.A. Oberli, M.W. Heartlein, F. DeRosa, R. Langer, D.G. Anderson, Synthesis and Biological Evaluation of Ionizable Lipid Materials for the In Vivo Delivery of Messenger RNA to B Lymphocytes, Advanced materials, 29 (2017).

[15] D. Schmid, C.G. Park, C.A. Hartl, N. Subedi, A.N. Cartwright, R.B. Puerto, Y. Zheng, J. Maiarana, G.J. Freeman, K.W. Wucherpfennig, D.J. Irvine, M.S. Goldberg, T cell-targeting nanoparticles focus delivery of immunotherapy to improve antitumor immunity, Nature Communications, 8 (2017) 1747.

[16] M. Kawai, T. Nakamura, N. Miura, M. Maeta, H. Tanaka, K. Ueda, K. Higashi, K. Moribe, K. Tange, Y. Nakai, H. Yoshioka, H. Harashima, H. Akita, DNA-loaded nano-adjuvant formed with a vitamin E-scaffold intracellular environmentally-responsive lipid-like material for cancer immunotherapy, Nanomedicine : nanotechnology, biology, and medicine, 14 (2018) 2587-2597.

[17] J. Yuan, G.Y. Ku, H.F. Gallardo, F. Orlandi, G. Manukian, T.S. Rasalan, Y. Xu, H. Li, S. Vyas, Z. Mu, P.B. Chapman, S.E. Krown, K. Panageas, S.L. Terzulli, L.J. Old, A.N. Houghton, J.D. Wolchok, Safety and immunogenicity of a human and mouse gp100 DNA vaccine in a phase I trial of patients with melanoma, Cancer immunity, 9 (2009) 5.

[18] J. Yuan, G.Y. Ku, M. Adamow, Z. Mu, S. Tandon, D. Hannaman, P. Chapman, G.

Schwartz, R. Carvajal, K.S. Panageas, A.N. Houghton, J.D. Wolchok, Immunologic responses to xenogeneic tyrosinase DNA vaccine administered by electroporation in patients with malignant melanoma, Journal for immunotherapy of cancer, 1 (2013) 20.

[19] T. Kurosaki, Y. Kodama, T. Muro, N. Higuchi, T. Nakamura, T. Kitahara, M. Miyakoda, K. Yui, H. Sasaki, Secure splenic delivery of plasmid DNA and its application to DNA vaccine, Biol Pharm Bull, 36 (2013) 1800-1806.

[20] T. Kurosaki, C. Nakasone, Y. Kodama, K. Egashira, H. Harasawa, T. Muro, H. Nakagawa, T. Kitahara, N. Higuchi, T. Nakamura, H. Sasaki, Splenic gene delivery system using selfassembling nano-complex with phosphatidylserine analog, Biol Pharm Bull, 38 (2015) 23-29.

[21] K. Tan, P. Cheang, I.A. Ho, P.Y. Lam, K.M. Hui, Nanosized bioceramic particles could function as efficient gene delivery vehicles with target specificity for the spleen, Gene Ther, 14 (2007) 828-835.

[22] J. Buck, P. Grossen, P.R. Cullis, J. Huwyler, D. Witzigmann, Lipid-Based DNA Therapeutics: Hallmarks of Non-Viral Gene Delivery, ACS nano, 13 (2019) 3754-3782.

[23] B. Garcia-Pinel, C. Porras-Alcala, A. Ortega-Rodriguez, F. Sarabia, J. Prados, C. Melguizo, J.M. Lopez-Romero, Lipid-Based Nanoparticles: Application and Recent Advances in Cancer Treatment, Nanomaterials, 9 (2019). 
[24] K. Kogure, R. Moriguchi, K. Sasaki, M. Ueno, S. Futaki, H. Harashima, Development of a non-viral multifunctional envelope-type nano device by a novel lipid film hydration method, $\mathrm{J}$ Control Release, 98 (2004) 317-323.

[25] K. Kogure, H. Akita, Y. Yamada, H. Harashima, Multifunctional envelope-type nano device (MEND) as a non-viral gene delivery system, Adv Drug Deliv Rev, 60 (2008) 559-571.

[26] I.A. Khalil, K. Kogure, S. Futaki, S. Hama, H. Akita, M. Ueno, H. Kishida, M. Kudoh, Y. Mishina, K. Kataoka, M. Yamada, H. Harashima, Octaarginine-modified multifunctional envelope-type nanoparticles for gene delivery, Gene Ther, 14 (2007) 682-689.

[27] I.A. Khalil, Y. Hayashi, R. Mizuno, H. Harashima, Octaarginine- and pH sensitive fusogenic peptide-modified nanoparticles for liver gene delivery, J Control Release, 156 (2011) 374-380.

[28] Y. Hayashi, J. Yamauchi, I.A. Khalil, K. Kajimoto, H. Akita, H. Harashima, Cell penetrating peptide-mediated systemic siRNA delivery to the liver, Int J Pharm, 419 (2011) 308313.

[29] Y. Hayashi, R. Mizuno, K.A. Ikramy, H. Akita, H. Harashima, Pretreatment of hepatocyte growth factor gene transfer mediated by octaarginine peptide-modified nanoparticles ameliorates LPS/D-galactosamine-induced hepatitis, Nucleic Acid Ther, 22 (2012) 360-363.

[30] K. Kusumoto, H. Akita, T. Ishitsuka, Y. Matsumoto, T. Nomoto, R. Furukawa, A. El-Sayed, H. Hatakeyama, K. Kajimoto, Y. Yamada, K. Kataoka, H. Harashima, Lipid envelope-type nanoparticle incorporating a multifunctional peptide for systemic siRNA delivery to the pulmonary endothelium, ACS Nano, 7 (2013) 7534-7541.

[31] M.M. Abd Elwakil, I.A. Khalil, Y.H.A. Elewa, K. Kusumoto, Y. Sato, N. Shobaki, Y. Kon, H. Harashima, Lung - Endothelium - Targeted Nanoparticles Based on a pH - Sensitive Lipid and the GALA Peptide Enable Robust Gene Silencing and the Regression of Metastatic Lung Cancer, Adv. Funct. Mater, (2019).

[32] I.A. Khalil, S. Kimura, Y. Sato, H. Harashima, Synergism between a cell penetrating peptide and a $\mathrm{pH}$-sensitive cationic lipid in efficient gene delivery based on double-coated nanoparticles, J Control Release, 275 (2018) 107-116.

[33] C. Lorenzer, M. Dirin, A.M. Winkler, V. Baumann, J. Winkler, Going beyond the liver: progress and challenges of targeted delivery of siRNA therapeutics, J Control Release, 203 (2015) 1-15.

[34] Y. Sato, H. Hatakeyama, Y. Sakurai, M. Hyodo, H. Akita, H. Harashima, A pH-sensitive cationic lipid facilitates the delivery of liposomal siRNA and gene silencing activity in vitro and in vivo, J Control Release, 163 (2012) 267-276. 
[35] F. de Meyer, B. Smit, Effect of cholesterol on the structure of a phospholipid bilayer, Proc Natl Acad Sci U S A, 106 (2009) 3654-3658.

[36] S.M. Moghimi, H.M. Patel, Tissue specific opsonins for phagocytic cells and their different affinity for cholesterol-rich liposomes, FEBS Lett, 233 (1988) 143-147.

[37] S. Moein Moghimi, I. Hamad, R. Bünger, T.L. Andresen, K. Jørgensen, A.C. Hunter, L. Baranji, L. Rosivall, J. Szebeni, Activation of the human complement system by cholesterol-rich and PEGylated liposomes-modulation of cholesterol-rich liposome-mediated complement activation by elevated serum LDL and HDL levels, J Liposome Res, 16 (2006) 167-174.

[38] T.M. Allen, P.R. Cullis, Liposomal drug delivery systems: from concept to clinical applications, Adv Drug Deliv Rev, 65 (2013) 36-48.

[39] B.L. Mui, Y.K. Tam, M. Jayaraman, S.M. Ansell, X. Du, Y.Y. Tam, P.J. Lin, S. Chen, J.K. Narayanannair, K.G. Rajeev, M. Manoharan, A. Akinc, M.A. Maier, P. Cullis, T.D. Madden, M.J. Hope, Influence of Polyethylene Glycol Lipid Desorption Rates on Pharmacokinetics and Pharmacodynamics of siRNA Lipid Nanoparticles, Mol Ther Nucleic Acids, 2 (2013) e139.

[40] I.A. Khalil, H. Harashima, An efficient PEGylated gene delivery system with improved targeting: Synergism between octaarginine and a fusogenic peptide, Int J Pharm, 538 (2018) 179187.

[41] X. Yan, F. Kuipers, L.M. Havekes, R. Havinga, B. Dontje, K. Poelstra, G.L. Scherphof, J.A. Kamps, The role of apolipoprotein $\mathrm{E}$ in the elimination of liposomes from blood by hepatocytes in the mouse, Biochem Biophys Res Commun, 328 (2005) 57-62.

[42] A. Sasaki, M. Kinjo, Monitoring intracellular degradation of exogenous DNA using diffusion properties, J Control Release, 143 (2010) 104-111.

[43] D. Lechardeur, A.S. Verkman, G.L. Lukacs, Intracellular routing of plasmid DNA during non-viral gene transfer, Adv Drug Deliv Rev, 57 (2005) 755-767.

[44] D. Lechardeur, K.J. Sohn, M. Haardt, P.B. Joshi, M. Monck, R.W. Graham, B. Beatty, J. Squire, H. O'Brodovich, G.L. Lukacs, Metabolic instability of plasmid DNA in the cytosol: a potential barrier to gene transfer, Gene Ther, 6 (1999) 482-497.

[45] B.K. Kim, G.B. Hwang, Y.B. Seu, J.S. Choi, K.S. Jin, K.O. Doh, DOTAP/DOPE ratio and cell type determine transfection efficiency with DOTAP-liposomes, Biochim Biophys Acta, 1848 (2015) 1996-2001.

[46] D. Bratosin, J. Mazurier, J.P. Tissier, J. Estaquier, J.J. Huart, J.C. Ameisen, D. Aminoff, J. Montreuil, Cellular and molecular mechanisms of senescent erythrocyte phagocytosis by macrophages. A review, Biochimie, 80 (1998) 173-195. 
[47] R. Bowles, S. Patil, H. Pincas, S.C. Sealfon, Optimized protocol for efficient transfection of dendritic cells without cell maturation, J Vis Exp, (2011) e2766.

[48] J.P. Namm, Q. Li, X. Lao, D.M. Lubman, J. He, Y. Liu, J. Zhu, S. Wei, A.E. Chang, B lymphocytes as effector cells in the immunotherapy of cancer, J Surg Oncol, 105 (2012) 431435.

[49] C. Corbo, R. Molinaro, F. Taraballi, N.E. Toledano Furman, M.B. Sherman, A. Parodi, F. Salvatore, E. Tasciotti, Effects of the protein corona on liposome-liposome and liposome-cell interactions, International journal of nanomedicine, 11 (2016) 3049-3063.

[50] A.C. Allison, N.E. Byars, Immunological adjuvants: desirable properties and side-effects, Mol Immunol, 28 (1991) 279-284. 


\section{Figure Legends}

\section{Figure 1.}

Comparison of gene expression of the YSK-MEND (Y) and the R8/YSK-MEND (RY) in different organs after IV injection to mice. Luciferase activities were measured at $6 \mathrm{hr}$ after injection and expressed as relative light units per $\mathrm{mg}$ of total proteins (RLU/mg protein). Each bar represents the mean +/-SD of at least 3 different experiments.

\section{Figure 2.}

Optimization of the lipid composition of the R8/YSK-MENDs. Mice were treated with different MENDs prepared with different amounts of lipid and lipid compositions. Luciferase activity in the spleen was measured at $6 \mathrm{hr}$ after injection and is expressed as relative light units per mg of total proteins (RLU/mg protein). Each bar represents the mean +/-SD of at least 3 different experiments.

\section{Figure 3.}

Comparison of MENDs prepared by 1-step or 2-step coating in vivo. Mice were treated with different MENDs prepared by 1-step or 2-step coating. (a) Luciferase activity in different organs,

(b) Biodistribution of different MENDs expressed as the percent of the dose per gram of tissue. Each bar represents the mean $+/-\mathrm{SD}$ of at least 3 different experiments (*p<0.05 vs. 1s). (c) Gene expression efficiency was calculated by dividing luciferase activity by the dose of MEND delivered per gram of tissue.

\section{Figure 4.}

Comparison of different MENDs prepared in the presence or absence of R8 or YSK05. (a) Schematic representation of the different forms of MENDs used. (b) Luciferase activities in different organs at $6 \mathrm{hr}$ after IV injection (expressed as RLU/mg protein). Each bar represents the 
mean +/-SD of at least 3 different experiments (*p<0.05 vs. RY2s (liver) and Y1s, RD2s (spleen), ${ }^{\#} \mathrm{P}<0.01$ vs. D1s, Y1s, RD2s (liver), D1s, Y1s, RD2s, RY2s (lung), and D1s (spleen)). (c) Biodistribution of different MENDs (expressed as \% ID/g tissue). Each bar represents the mean +/-SD of at least 3 different experiments ( ${ }^{*} \mathrm{p}<0.05$ vs. D1s, Y1s, RD2s, RY2s (lung), ${ }^{\Delta} \mathrm{P}<0.01$ vs. Y1s (spleen)). (d) Gene expression efficiency was calculated by dividing luciferase activity by the dose of MEND delivered per gram of tissue.

\section{Figure 5.}

Spleen cell type taking up the R8/YSK-MEND system. At $6 \mathrm{hr}$ after the injection of the DiD labeled R8/YSK-MEND, mouse spleens were dissected and dispersed into single cells. The splenocytes were stained with several antibodies and then analyzed by flow cytometry (a). The total fluorescence (b) as well as the percent positive cells (c) were determined in each case. Each bar represents the mean $+/$ - SD of 3 different experiments ( $* * \mathrm{P}<0.01$ vs. $\mathrm{T}$ cells, DCs and macrophages).

\section{Figure 6.}

In vivo anti-tumor effect of R8/YSK-MEND encapsulating antigen (OVA)-coding pDNA. (a) Prophylactic effect: C57BL/6 mice were injected twice with the R8/YSK-MEND encapsulating OVA-coding pDNA (RY OVA) on 7 and 14 days before tumor inoculation. The mice were inoculated with E.G7-OVA cells and the tumor volume was monitored. Mice groups treated with PBS, naked OVA-coding pDNA (naked pOVA), and R8/YSK-MEND encapsulating luciferasecoding pDNA (RY Luc) were used as different controls. (b) Therapeutic effect: C57BL/6 mice were inoculated with E.G7-OVA cells and different samples were injected at 7, 10 and 14 days after tumor inoculation. The plots represent the mean $+/$-SD (a total of 6 mice/group) $(* \mathrm{P}<0.05$, $* * \mathrm{P}<0.01)$. 


\section{Figure 7.}

In vivo toxicity and immune stimulation of R8/YSK-MEND. (a) In vivo toxicity: ICR mice were injected with naked Luc pDNA or pDNA encapsulated in R8/YSK-MEND. Different biomarkers were measured in the serum $6 \mathrm{hr}$ after injection (neutralized to mice treated with PBS). Each column represents the mean +/-SD (n=3). (b) Measurement of IL-6 levels in the serum $1 \mathrm{hr}$ after injection of PBS, naked pOVA, or R8/YSK-MEND encapsulating pLuc or pOVA. Each column represents the mean +/-SD (n=3). BUN: Blood urea nitrogen; CRE: Creatinine; AST: Aspartate aminotransferase; ALT: Alanine aminotransferase; ALP: Alkaline phosphatase; LDH: Lactate dehydrogenase; CK: Creatine kinase. 


\section{Tables}

\section{Table 1.}

Composition and characterization of the different MENDs prepared by a 2-step coating

\begin{tabular}{lcccc}
\hline & Lipid Composition $^{\text {a) }}$ & Diameter $^{\text {b) }[\mathrm{nm}]}$ & PDI & Z-potential [mV] \\
\hline YSK-MEND (Y) & $\begin{array}{c}\text { First coat; DOPE } \\
\text { R8/YSK-MEND (RY) }\end{array}$ & $181.6 \pm 8$ & $0.314 \pm 0.07$ & $(-) 14.4 \pm 3.8$ \\
& $\begin{array}{c}\text { Second coat; YSK05/Chol/PEG (78.5/20/1.5) } \\
\text { First coat; DOPE/STR-R8 (97.75/2.25) } \\
\text { Second coat; YSK05/Chol/PEG (78.5/20/1.5) }\end{array}$ & $201.8 \pm 32$ & $0.340 \pm 0.05$ & $(-) 21.5 \pm 4.2$ \\
\hline
\end{tabular}

${ }^{\text {a) }}$ First coat/Second coat $=1 / 1(\mathrm{nmol} / \mathrm{nmol}) ;{ }^{\mathrm{b})}$ Values are mean $\pm \mathrm{SD}$ of at least three different preparations

\section{Table 2}

Composition and characterization of different MENDs prepared by a 1-step or a 2-step coating

\begin{tabular}{lcccc}
\hline & Lipid Composition $^{\text {a) }}$ & Diameter $^{\text {b) }}[\mathrm{nm}]$ & PDI & Z-potential [mV] \\
\hline 1-step coating & $\begin{array}{c}\text { DOPE/STR-R8/YSK05/Chol/PEG } \\
(47.75 / 2.25 / 34.25 / 14.25 / 1.5)\end{array}$ & $216.7 \pm 36.1$ & $0.374 \pm 0.030$ & $(-) 12.5 \pm 4.5$ \\
2-step coating & $\begin{array}{c}\text { First coat; DOPE/STR-R8 (95.5/4.5) } \\
\text { Second coat; YSK05/Chol/PEG (68.5/28.5/3) }\end{array}$ & $155.9 \pm 18.0$ & $0.251 \pm 0.066$ & $(-) 14.2 \pm 13.9$ \\
\hline
\end{tabular}

${ }^{\mathrm{a})}$ First coat/Second coat $=1 / 1(\mathrm{nmol} / \mathrm{nmol}) ;{ }^{\mathrm{b}}$ Values are mean \pm SD of at least three different preparations

\section{Table 3}

Composition and characterization of the different MENDs prepared with or without YSK05 or R8

\begin{tabular}{|c|c|c|c|c|}
\hline & Lipid Composition & $\begin{array}{l}\text { Diameter } \\
\quad(\mathrm{nm})\end{array}$ & PDI & $\begin{array}{l}\text { Z-potential } \\
\quad(\mathrm{mV})\end{array}$ \\
\hline $\begin{array}{l}\text { DOTAP-MEND } \\
\text { (1-step coating) (D1s) }\end{array}$ & $\begin{array}{l}\text { DOPE/DOTAP/Chol/PEG } \\
(50 / 34.25 / 14.25 / 1.5)\end{array}$ & $164.7 \pm 25.6$ & $0.284 \pm 0.098$ & (-) $12.4 \pm 7.9$ \\
\hline $\begin{array}{l}\text { YSK-MEND } \\
\text { (1-step coating) (Y1s) }\end{array}$ & DOPE/YSK05/Chol/PEG (50/34.25/14.25/1.5) & $212.8 \pm 54.0$ & $0.373 \pm 0.068$ & (-) $16.8 \pm 5.8$ \\
\hline $\begin{array}{l}\text { R8/DOTAP-MEND } \\
\text { (2-step coating) (RD2s) }\end{array}$ & $\begin{array}{c}\text { First coat; DOPE/STR-R8 }(95.5 / 4.5) \\
\text { Second coat; DOTAP/Chol/PEG }(68.5 / 28.5 / 3)\end{array}$ & $157.3 \pm 10.7$ & $0.262 \pm 0.040$ & (-) $19.9 \pm 3.8$ \\
\hline $\begin{array}{l}\text { R8/YSK-MEND } \\
\text { (2-step coating) (RY2s) }\end{array}$ & $\begin{array}{c}\text { First coat; DOPE/STR-R8 }(95.5 / 4.5) \\
\text { Second coat; YSK05/Chol/PEG }(68.5 / 28.5 / 3)\end{array}$ & $162.3 \pm 14.9$ & $0.232 \pm 0.027$ & (-) $16.8 \pm 5.9$ \\
\hline
\end{tabular}




\section{References Automated List}

[1] M. Collins, A. Thrasher, Gene therapy: progress and predictions, Proc Biol Sci, 282 (2015) 20143003.

[2] K.B. Kaufmann, H. Büning, A. Galy, A. Schambach, M. Grez, Gene therapy on the move, EMBO Mol Med, 5 (2013) 1642-1661.

[3] A. Mountain, Gene therapy: the first decade, Trends Biotechnol, 18 (2000) 119-128.

[4] H. Yin, R.L. Kanasty, A.A. Eltoukhy, A.J. Vegas, J.R. Dorkin, D.G. Anderson, Non-viral vectors for gene-based therapy, Nat Rev Genet, 15 (2014) 541-555.

[5] M. Elsabahy, A. Nazarali, M. Foldvari, Non-viral nucleic acid delivery: key challenges and future directions, Curr Drug Deliv, 8 (2011) 235-244.

[6] F. Alexis, E. Pridgen, L.K. Molnar, O.C. Farokhzad, Factors affecting the clearance and biodistribution of polymeric nanoparticles, Mol Pharm, 5 (2008) 505-515.

[7] I.A. Khalil, K. Kogure, H. Akita, H. Harashima, Uptake pathways and subsequent intracellular trafficking in nonviral gene delivery, Pharmacol Rev, 58 (2006) 32-45.

[8] A.B. Jindal, Nanocarriers for spleen targeting: anatomo-physiological considerations, formulation strategies and therapeutic potential, Drug Deliv Transl Res, 6 (2016) 473-485. [9] L. Shen, S. Tenzer, W. Storck, D. Hobernik, V.K. Raker, K. Fischer, S. Decker, A. Dzionek, S. Krauthäuser, M. Diken, A. Nikolaev, J. Maxeiner, P. Schuster, C. Kappel, A. Verschoor, H. Schild, S. Grabbe, M. Bros, Protein corona-mediated targeting of nanocarriers to B cells allows redirection of allergic immune responses, J Allergy Clin Immunol, (2018).

[10] J.L. Schultze, S. Grabbe, M.S. von Bergwelt-Baildon, DCs and CD40-activated B cells: current and future avenues to cellular cancer immunotherapy, Trends in immunology, 25 (2004) 659-664.

[11] J.O. Jin, H. Park, W. Zhang, J.W. de Vries, A. Gruszka, M.W. Lee, D.R. Ahn, A. Herrmann, M. Kwak, Modular delivery of CpG-incorporated lipid-DNA nanoparticles for spleen DC activation, Biomaterials, 115 (2017) 81-89.

[12] R.A.M. Rossetti, N.P.C. Lorenzi, K. Yokochi, M. Rosa, L. Benevides, P.F.R. Margarido, E.C. Baracat, J.P. Carvalho, L.L. Villa, A.P. Lepique, B lymphocytes can be activated to act as antigen presenting cells to promote anti-tumor responses, PloS one, 13 (2018) e0199034.

[13] V.T. Colluru, D.G. McNeel, B lymphocytes as direct antigen-presenting cells for anti-tumor DNA vaccines, Oncotarget, 7 (2016) 67901-67918.

[14] O.S. Fenton, K.J. Kauffman, J.C. Kaczmarek, R.L. McClellan, S. Jhunjhunwala, M.W. Tibbitt, M.D. Zeng, E.A. Appel, J.R. Dorkin, F.F. Mir, J.H. Yang, M.A. Oberli, M.W. Heartlein, F. DeRosa, R. Langer, D.G. Anderson, Synthesis and Biological Evaluation of Ionizable Lipid Materials for the In Vivo Delivery of Messenger RNA to B Lymphocytes, Advanced materials, 29 (2017).

[15] D. Schmid, C.G. Park, C.A. Hartl, N. Subedi, A.N. Cartwright, R.B. Puerto, Y. Zheng, J. Maiarana, G.J. Freeman, K.W. Wucherpfennig, D.J. Irvine, M.S. Goldberg, T cell-targeting nanoparticles focus delivery of immunotherapy to improve antitumor immunity, Nature Communications, 8 (2017) 1747.

[16] M. Kawai, T. Nakamura, N. Miura, M. Maeta, H. Tanaka, K. Ueda, K. Higashi, K. Moribe, K. Tange, Y. Nakai, H. Yoshioka, H. Harashima, H. Akita, DNA-loaded nano-adjuvant formed with a vitamin E-scaffold intracellular environmentally-responsive lipid-like material for cancer immunotherapy, Nanomedicine : nanotechnology, biology, and medicine, 14 (2018) 2587-2597. 
[17] J. Yuan, G.Y. Ku, H.F. Gallardo, F. Orlandi, G. Manukian, T.S. Rasalan, Y. Xu, H. Li, S. Vyas, Z. Mu, P.B. Chapman, S.E. Krown, K. Panageas, S.L. Terzulli, L.J. Old, A.N. Houghton, J.D. Wolchok, Safety and immunogenicity of a human and mouse gp100 DNA vaccine in a phase I trial of patients with melanoma, Cancer immunity, 9 (2009) 5.

[18] J. Yuan, G.Y. Ku, M. Adamow, Z. Mu, S. Tandon, D. Hannaman, P. Chapman, G.

Schwartz, R. Carvajal, K.S. Panageas, A.N. Houghton, J.D. Wolchok, Immunologic responses to xenogeneic tyrosinase DNA vaccine administered by electroporation in patients with malignant melanoma, Journal for immunotherapy of cancer, 1 (2013) 20.

[19] T. Kurosaki, Y. Kodama, T. Muro, N. Higuchi, T. Nakamura, T. Kitahara, M. Miyakoda, K. Yui, H. Sasaki, Secure splenic delivery of plasmid DNA and its application to DNA vaccine, Biol Pharm Bull, 36 (2013) 1800-1806.

[20] T. Kurosaki, C. Nakasone, Y. Kodama, K. Egashira, H. Harasawa, T. Muro, H. Nakagawa, T. Kitahara, N. Higuchi, T. Nakamura, H. Sasaki, Splenic gene delivery system using selfassembling nano-complex with phosphatidylserine analog, Biol Pharm Bull, 38 (2015) 23-29. [21] K. Tan, P. Cheang, I.A. Ho, P.Y. Lam, K.M. Hui, Nanosized bioceramic particles could function as efficient gene delivery vehicles with target specificity for the spleen, Gene Ther, 14 (2007) 828-835.

[22] J. Buck, P. Grossen, P.R. Cullis, J. Huwyler, D. Witzigmann, Lipid-Based DNA

Therapeutics: Hallmarks of Non-Viral Gene Delivery, ACS nano, 13 (2019) 3754-3782.

[23] B. Garcia-Pinel, C. Porras-Alcala, A. Ortega-Rodriguez, F. Sarabia, J. Prados, C. Melguizo, J.M. Lopez-Romero, Lipid-Based Nanoparticles: Application and Recent Advances in Cancer Treatment, Nanomaterials, 9 (2019).

[24] K. Kogure, R. Moriguchi, K. Sasaki, M. Ueno, S. Futaki, H. Harashima, Development of a non-viral multifunctional envelope-type nano device by a novel lipid film hydration method, $\mathrm{J}$ Control Release, 98 (2004) 317-323.

[25] K. Kogure, H. Akita, Y. Yamada, H. Harashima, Multifunctional envelope-type nano device (MEND) as a non-viral gene delivery system, Adv Drug Deliv Rev, 60 (2008) 559-571.

[26] I.A. Khalil, K. Kogure, S. Futaki, S. Hama, H. Akita, M. Ueno, H. Kishida, M. Kudoh, Y. Mishina, K. Kataoka, M. Yamada, H. Harashima, Octaarginine-modified multifunctional envelope-type nanoparticles for gene delivery, Gene Ther, 14 (2007) 682-689.

[27] I.A. Khalil, Y. Hayashi, R. Mizuno, H. Harashima, Octaarginine- and pH sensitive fusogenic peptide-modified nanoparticles for liver gene delivery, J Control Release, 156 (2011) 374-380.

[28] Y. Hayashi, J. Yamauchi, I.A. Khalil, K. Kajimoto, H. Akita, H. Harashima, Cell penetrating peptide-mediated systemic siRNA delivery to the liver, Int J Pharm, 419 (2011) 308313.

[29] Y. Hayashi, R. Mizuno, K.A. Ikramy, H. Akita, H. Harashima, Pretreatment of hepatocyte growth factor gene transfer mediated by octaarginine peptide-modified nanoparticles ameliorates LPS/D-galactosamine-induced hepatitis, Nucleic Acid Ther, 22 (2012) 360-363.

[30] K. Kusumoto, H. Akita, T. Ishitsuka, Y. Matsumoto, T. Nomoto, R. Furukawa, A. El-Sayed, H. Hatakeyama, K. Kajimoto, Y. Yamada, K. Kataoka, H. Harashima, Lipid envelope-type nanoparticle incorporating a multifunctional peptide for systemic siRNA delivery to the pulmonary endothelium, ACS Nano, 7 (2013) 7534-7541.

[31] M.M. Abd Elwakil, I.A. Khalil, Y.H.A. Elewa, K. Kusumoto, Y. Sato, N. Shobaki, Y. Kon, H. Harashima, Lung - Endothelium - Targeted Nanoparticles Based on a pH - Sensitive Lipid 
and the GALA Peptide Enable Robust Gene Silencing and the Regression of Metastatic Lung Cancer, Adv. Funct. Mater, (2019).

[32] I.A. Khalil, S. Kimura, Y. Sato, H. Harashima, Synergism between a cell penetrating peptide and a $\mathrm{pH}$-sensitive cationic lipid in efficient gene delivery based on double-coated nanoparticles, J Control Release, 275 (2018) 107-116.

[33] C. Lorenzer, M. Dirin, A.M. Winkler, V. Baumann, J. Winkler, Going beyond the liver: progress and challenges of targeted delivery of siRNA therapeutics, J Control Release, 203 (2015) 1-15.

[34] Y. Sato, H. Hatakeyama, Y. Sakurai, M. Hyodo, H. Akita, H. Harashima, A pH-sensitive cationic lipid facilitates the delivery of liposomal siRNA and gene silencing activity in vitro and in vivo, J Control Release, 163 (2012) 267-276.

[35] F. de Meyer, B. Smit, Effect of cholesterol on the structure of a phospholipid bilayer, Proc Natl Acad Sci U S A, 106 (2009) 3654-3658.

[36] S.M. Moghimi, H.M. Patel, Tissue specific opsonins for phagocytic cells and their different affinity for cholesterol-rich liposomes, FEBS Lett, 233 (1988) 143-147.

[37] S. Moein Moghimi, I. Hamad, R. Bünger, T.L. Andresen, K. Jørgensen, A.C. Hunter, L. Baranji, L. Rosivall, J. Szebeni, Activation of the human complement system by cholesterol-rich and PEGylated liposomes-modulation of cholesterol-rich liposome-mediated complement activation by elevated serum LDL and HDL levels, J Liposome Res, 16 (2006) 167-174. [38] T.M. Allen, P.R. Cullis, Liposomal drug delivery systems: from concept to clinical applications, Adv Drug Deliv Rev, 65 (2013) 36-48.

[39] B.L. Mui, Y.K. Tam, M. Jayaraman, S.M. Ansell, X. Du, Y.Y. Tam, P.J. Lin, S. Chen, J.K. Narayanannair, K.G. Rajeev, M. Manoharan, A. Akinc, M.A. Maier, P. Cullis, T.D. Madden, M.J. Hope, Influence of Polyethylene Glycol Lipid Desorption Rates on Pharmacokinetics and Pharmacodynamics of siRNA Lipid Nanoparticles, Mol Ther Nucleic Acids, 2 (2013) e139. [40] I.A. Khalil, H. Harashima, An efficient PEGylated gene delivery system with improved targeting: Synergism between octaarginine and a fusogenic peptide, Int J Pharm, 538 (2018) 179187.

[41] X. Yan, F. Kuipers, L.M. Havekes, R. Havinga, B. Dontje, K. Poelstra, G.L. Scherphof, J.A. Kamps, The role of apolipoprotein $\mathrm{E}$ in the elimination of liposomes from blood by hepatocytes in the mouse, Biochem Biophys Res Commun, 328 (2005) 57-62.

[42] A. Sasaki, M. Kinjo, Monitoring intracellular degradation of exogenous DNA using diffusion properties, J Control Release, 143 (2010) 104-111.

[43] D. Lechardeur, A.S. Verkman, G.L. Lukacs, Intracellular routing of plasmid DNA during non-viral gene transfer, Adv Drug Deliv Rev, 57 (2005) 755-767.

[44] D. Lechardeur, K.J. Sohn, M. Haardt, P.B. Joshi, M. Monck, R.W. Graham, B. Beatty, J. Squire, H. O'Brodovich, G.L. Lukacs, Metabolic instability of plasmid DNA in the cytosol: a potential barrier to gene transfer, Gene Ther, 6 (1999) 482-497.

[45] B.K. Kim, G.B. Hwang, Y.B. Seu, J.S. Choi, K.S. Jin, K.O. Doh, DOTAP/DOPE ratio and cell type determine transfection efficiency with DOTAP-liposomes, Biochim Biophys Acta, 1848 (2015) 1996-2001.

[46] D. Bratosin, J. Mazurier, J.P. Tissier, J. Estaquier, J.J. Huart, J.C. Ameisen, D. Aminoff, J. Montreuil, Cellular and molecular mechanisms of senescent erythrocyte phagocytosis by macrophages. A review, Biochimie, 80 (1998) 173-195.

[47] R. Bowles, S. Patil, H. Pincas, S.C. Sealfon, Optimized protocol for efficient transfection of dendritic cells without cell maturation, J Vis Exp, (2011) e2766. 
[48] J.P. Namm, Q. Li, X. Lao, D.M. Lubman, J. He, Y. Liu, J. Zhu, S. Wei, A.E. Chang, B lymphocytes as effector cells in the immunotherapy of cancer, J Surg Oncol, 105 (2012) 431435.

[49] C. Corbo, R. Molinaro, F. Taraballi, N.E. Toledano Furman, M.B. Sherman, A. Parodi, F. Salvatore, E. Tasciotti, Effects of the protein corona on liposome-liposome and liposome-cell interactions, International journal of nanomedicine, 11 (2016) 3049-3063.

[50] A.C. Allison, N.E. Byars, Immunological adjuvants: desirable properties and side-effects, Mol Immunol, 28 (1991) 279-284. 


\section{Supporting Information}

Journal of Controlled Release - Research Article - Ms. Ref. No.: JCR-D-19-00580

\section{Spleen Selective Enhancement of Transfection Activities of Plasmid DNA Driven by Octaarginine and an Ionizable Lipid and its Implications for Cancer Immunization}

Seigo Kimura ${ }^{a}$, Ikramy A. Khalil ${ }^{a, b, *}$, Yaser H. A. Elewa ${ }^{c, d}$, and Hideyoshi Harashima ${ }^{a, e, *}$

${ }^{a}$ Laboratory of Innovative Nanomedicine, Faculty of Pharmaceutical Sciences, Hokkaido University, Kita-12, Nishi-6, Kita-ku, Sapporo 060-0812, Japan

${ }^{b}$ Department of Pharmaceutics, Faculty of Pharmacy, Assiut University, Assiut 71526, Egypt ${ }^{c}$ Department of Histology and Cytology, Faculty of Veterinary Medicine, Zagazig University, Zagazig, Egypt

${ }^{d}$ Laboratory of Anatomy, Department of Biomedical Sciences, Graduate School of Veterinary Medicine, Hokkaido University, Kita 18, Nishi 9, Kita-ku, Sapporo 060-0818, Japan ${ }^{e}$ Laboratory for Molecular Design of Pharmaceutics, Faculty of Pharmaceutical Sciences, Hokkaido University, Kita-12, Nishi-6, Kita-ku, Sapporo 060-0812, Japan 

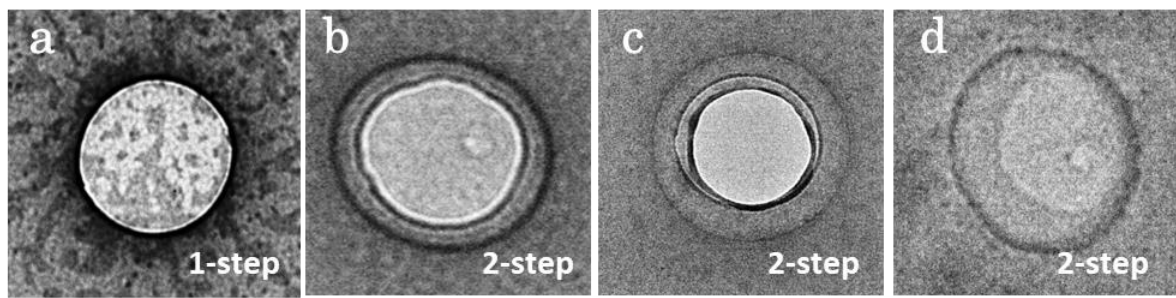

Figure S1.

TEM images of R8/YSK-MEND prepared with 1-step (a) or 2-step coating (b-d). 
a

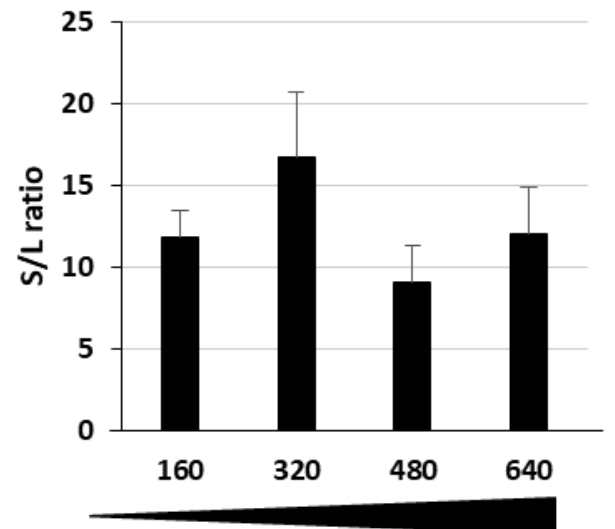

C Total lipid (nmol)

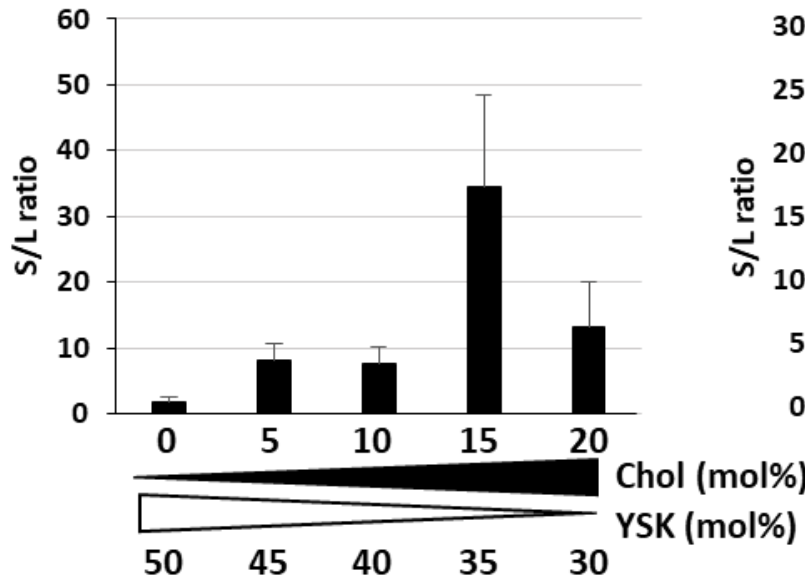

$\mathrm{b}$
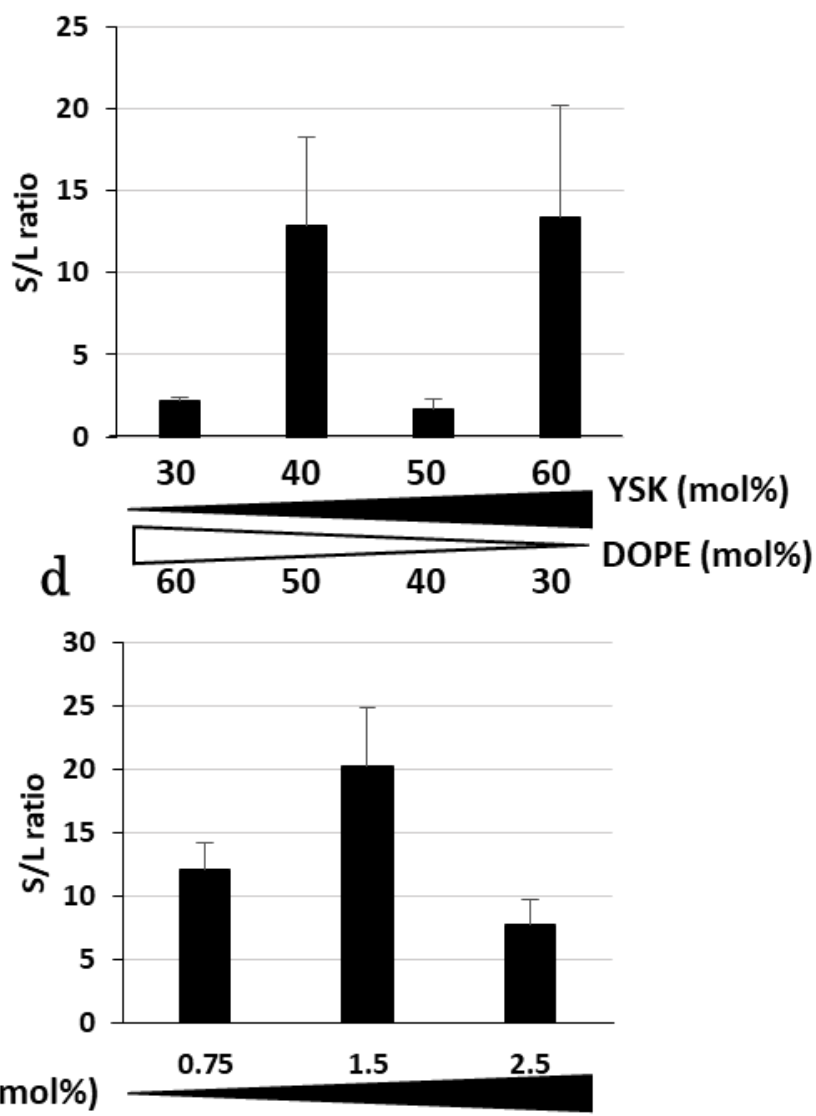

DMG-PEG (mol\%)

\section{Figure S2.}

Evaluation of spleen selectivity of different R8/YSK-MENDs

Mice were treated with different R8/YSK-MENDs and the luciferase activity in the liver and spleen was measured at $6 \mathrm{hr}$ after injection (expressed as RLU/mg of protein). The ratio of spleen/liver luciferase activity ( $\mathrm{S} / \mathrm{L}$ ratio) is calculated by dividing the spleen luciferase activity by the liver luciferase activity. Each bar represents the mean +/-SEM of at least 3 different experiments. 


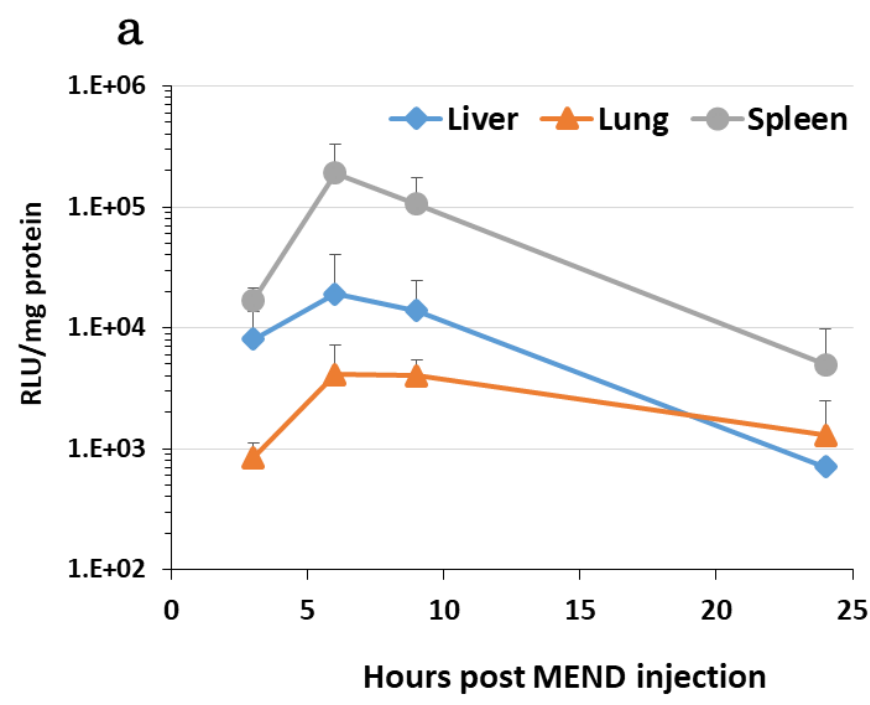

b

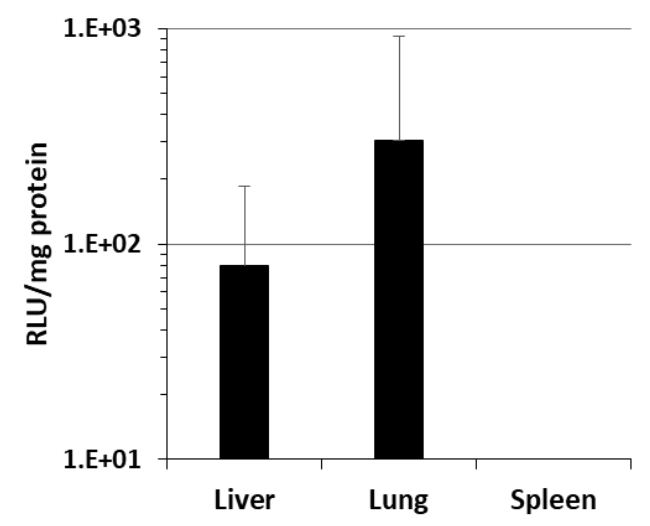

\section{Figure S3.}

(a) Luciferase activities were measured in different organs at different times after the injection of the optimized R8/YSK-MEND. Luciferase activities were expressed as relative light units per $\mathrm{mg}$ of total proteins (RLU/mg protein). Each pint represents the mean +/-SD of 3 different experiments. (b) Gene expression in different organs was measured $6 \mathrm{hr}$ after injection of naked Luc-encoding pDNA. 
a
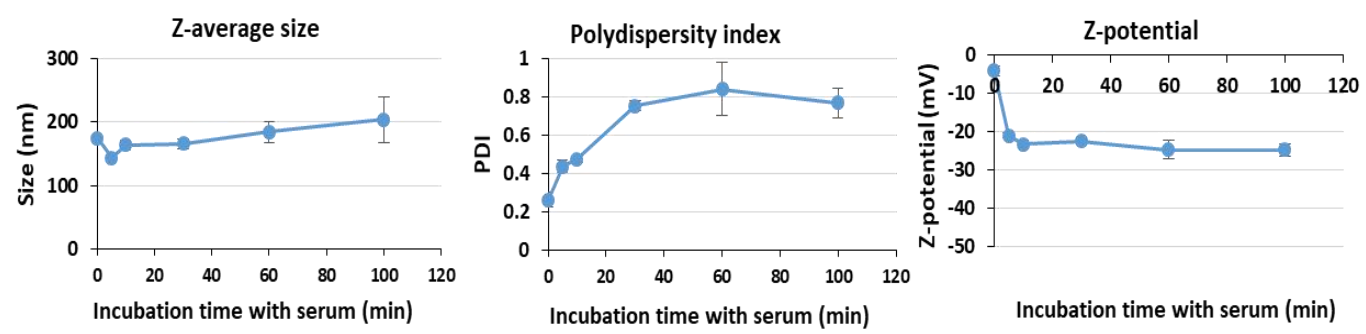

$\mathrm{b}$
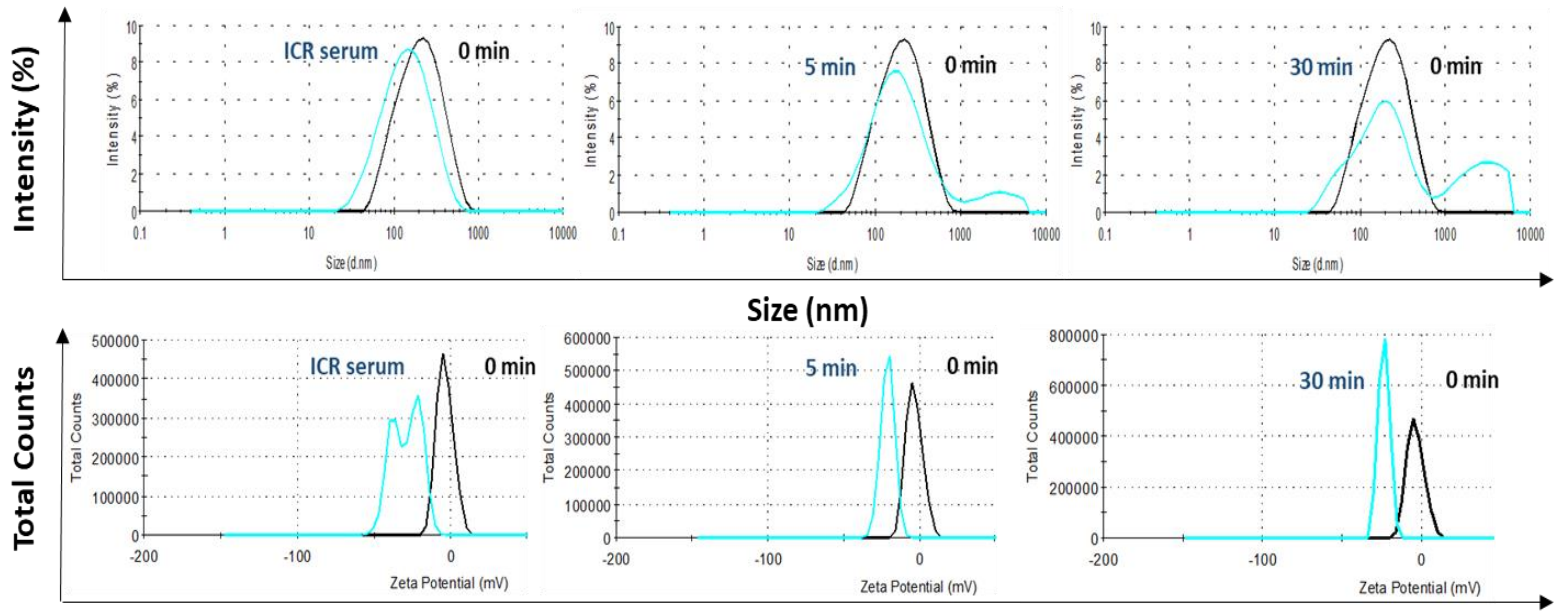

Zeta Potential (mV)

C
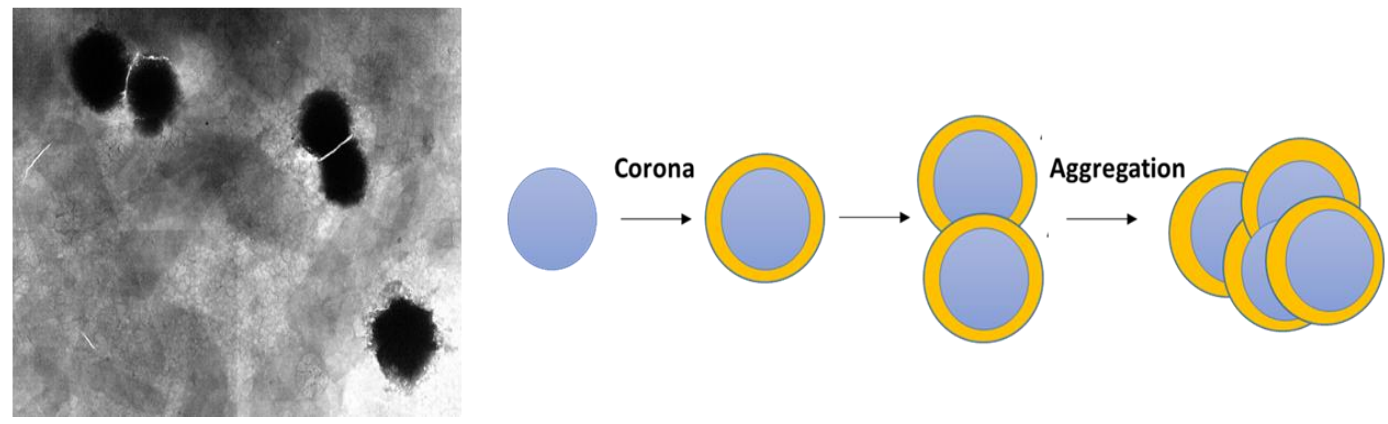

Figure S4.

(a) Effect of serum incubation on the physicochemical characterization of the optimized R8/YSK-MEND. (b) DLS histograms of R8/YSK-MEND incubated with serum for different times. (c) A representative TEM image of nanoparticles incubated with serum for 5 min at $37^{\circ} \mathrm{C}$. 

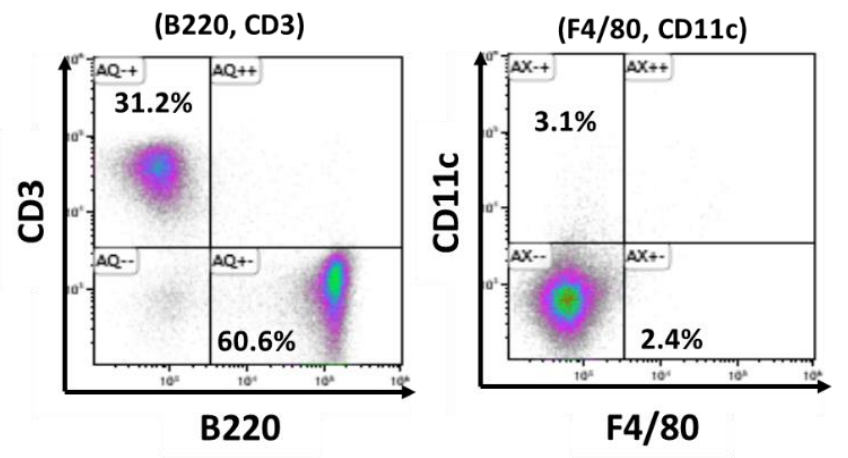

(B220, CD3)

$(+,-) \rightarrow$ B cell

$(-,+) \rightarrow$ T cell

(F4/80, CD11C)

$(+,-) \rightarrow$ Macrophage

$(-,+) \rightarrow$ Dendritic cell

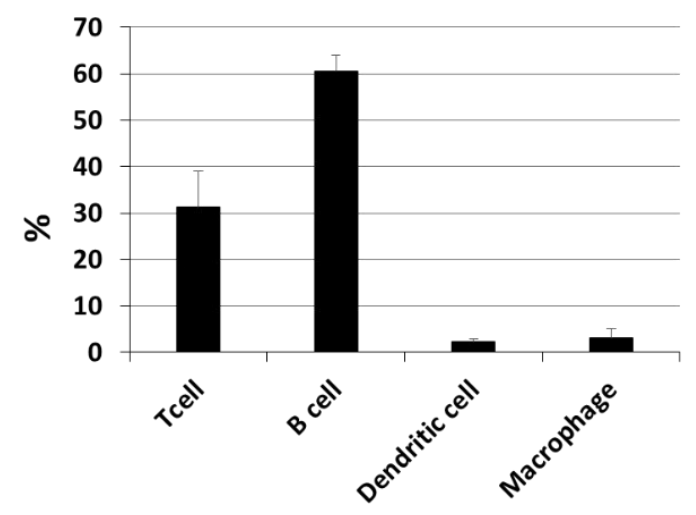

\section{Figure S5. Spleen cell distribution}

Mouse spleens were dissected and isolated into single cells. The splenocytes were stained with several antibodies and then analyzed by flow cytometry. Each bar represents the mean +/-SD of 3 different experiments. 

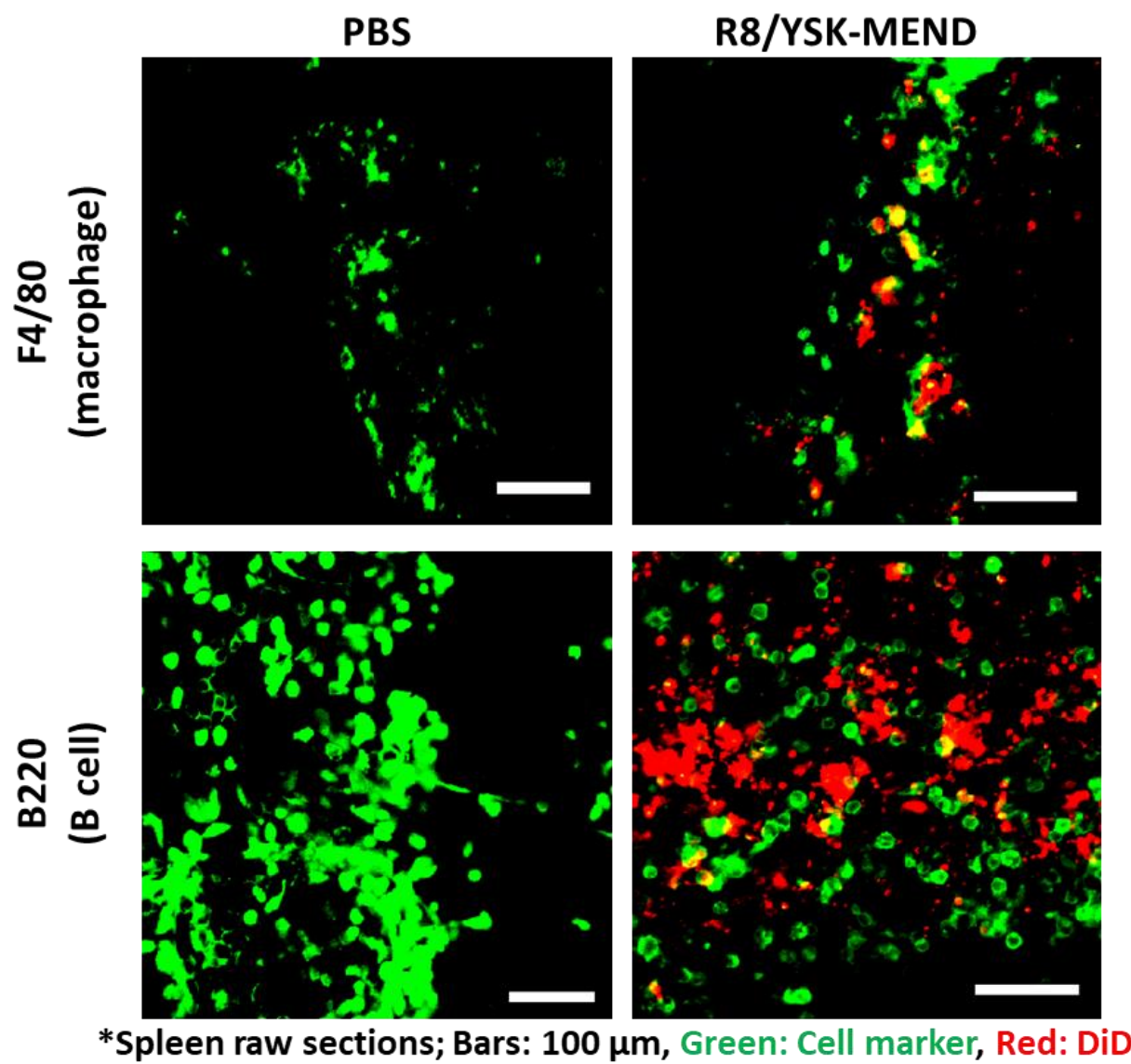

\section{Figure S6}

Confocal scanning microscopy of the distribution of the MEND system in the spleen. The MEND system was labeled with DiD fluorescence. Spleen sections were incubated with different antibodies (green) to identify macrophages or B cells. 


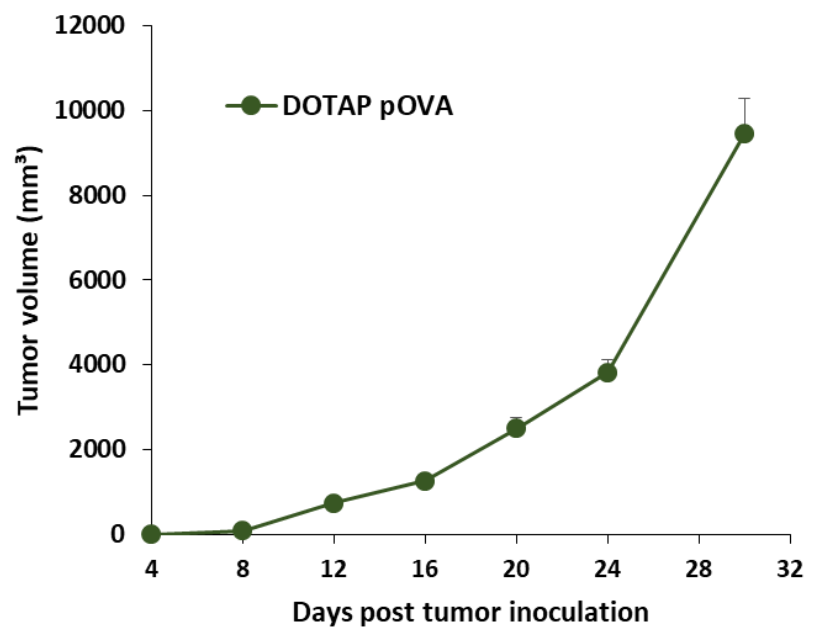

Figure S7.

Investigating the prophylactic anti-tumor effect of DOTAP-MEND system encapsulating pOVA. 


\section{Table S1}

\begin{tabular}{|c|c|c|c|c|c|}
\hline Total lipid [nmol] & \multicolumn{2}{|c|}{ Diameter [nm] } & & PDI & Z-potential [mV] \\
\hline 160 & \multicolumn{2}{|c|}{$282.7 \pm 67.1$} & \multicolumn{2}{|c|}{$0.404 \pm 0.084$} & (-) $13.2 \pm 8.1$ \\
\hline 320 & \multicolumn{2}{|c|}{$181.1 \pm 9.9$} & \multicolumn{2}{|c|}{$0.239 \pm 0.067$} & $(-) 10.0 \pm 13.5$ \\
\hline 480 & \multicolumn{2}{|c|}{$161.5 \pm 6.0$} & \multicolumn{2}{|c|}{$0.238 \pm 0.031$} & $(-) 8.6 \pm 16.2$ \\
\hline 640 & \multicolumn{2}{|c|}{$162.7 \pm 20.6$} & \multicolumn{2}{|c|}{$0.238 \pm 0.045$} & $(-) 9.8 \pm 16.6$ \\
\hline \multicolumn{2}{|c|}{ YSK/DOPE [mol\%/mol\%] } & \multicolumn{2}{|c|}{ Diameter [nm] } & PDI & Z-potential [mV] \\
\hline \multicolumn{2}{|l|}{$30 / 60$} & \multicolumn{2}{|c|}{$161.8 \pm 10.3$} & $0.223 \pm 0.057$ & $(-) 1.4 \pm 2.2$ \\
\hline \multicolumn{2}{|l|}{$40 / 50$} & \multicolumn{2}{|c|}{$163.3 \pm 5.7$} & $0.224 \pm 0.036$ & $(-) 2.2 \pm 3.5$ \\
\hline \multicolumn{2}{|l|}{$50 / 40$} & \multicolumn{2}{|c|}{$166.0 \pm 10.5$} & $0.220 \pm 0.017$ & $(-) 2.5 \pm 3.7$ \\
\hline \multicolumn{2}{|l|}{$60 / 30$} & \multicolumn{2}{|c|}{$202.7 \pm 63.8$} & $0.206 \pm 0.028$ & $(-) 7.3 \pm 4.9$ \\
\hline \multicolumn{2}{|c|}{ Chol/YSK [mol\%/mol\%] } & \multicolumn{2}{|c|}{ Diameter [nm] } & PDI & Z-potential [mV] \\
\hline \multicolumn{2}{|l|}{$0 / 50$} & \multicolumn{2}{|c|}{$226.4 \pm 75.1$} & $0.227 \pm 0.092$ & (-) $5.1 \pm 6.0$ \\
\hline \multicolumn{2}{|l|}{$5 / 45$} & \multicolumn{2}{|c|}{$172.5 \pm 13.6$} & $0.194 \pm 0.034$ & $(-) 1.3 \pm 3.3$ \\
\hline \multicolumn{2}{|l|}{$10 / 40$} & \multicolumn{2}{|c|}{$163.9 \pm 10.1$} & $0.179 \pm 0.019$ & $(-) 2.8 \pm 3.8$ \\
\hline \multicolumn{2}{|l|}{$15 / 35$} & \multicolumn{2}{|c|}{$176.6 \pm 12.3$} & $0.223 \pm 0.016$ & (-) $1.8 \pm 0.6$ \\
\hline \multicolumn{2}{|l|}{$20 / 30$} & \multicolumn{2}{|c|}{$167.8 \pm 6.3$} & $0.182 \pm 0.010$ & $(-) 2.7 \pm 3.9$ \\
\hline \multicolumn{2}{|c|}{ DMG-PEG [mol\%] } & \multicolumn{2}{|c|}{ Diameter [nm] } & PDI & Z-potential [mV] \\
\hline \multicolumn{2}{|l|}{0.75} & \multicolumn{2}{|c|}{$173.3 \pm 8.6$} & $0.229 \pm 0.032$ & $(-) 14.1 \pm 13.7$ \\
\hline \multicolumn{2}{|l|}{1.5} & $160.3 \pm$ & & $0.244 \pm 0.024$ & $(-) 10.1 \pm 12.0$ \\
\hline 2.5 & & $160.6 \pm$ & & $0.238 \pm 0.035$ & (-) $9.4 \pm 7.6$ \\
\hline
\end{tabular}




\section{Table S2}

MEND characterization of the optimized compared to the original condition

\begin{tabular}{lcc}
\hline & original condition & optimized condition \\
\hline Total lipid for pDNA 15 $\mu \mathrm{g}$ & $640 \mathrm{nmol}$ & $320 \mathrm{nmol}$ \\
STR-R8 amount for pDNA 15 $\mu \mathrm{g}$ & $7.2 \mathrm{nmol}$ & $7.2 \mathrm{nmol}$ \\
YSK05 molar ratio & $39.25 \%^{*}$ & $34.25 \%{ }^{*}$ \\
DOPE molar ratio & $48.88 \%$ & $47.75 \%$ \\
Cholesterol molar ratio & $10.00 \%$ & $14.25 \%$ \\
DMG-PEG2000 molar ratio & $0.75 \%$ & $1.50 \%$ \\
Diameter (nm) & 201.8 & 160.3 \\
Polydispersity index (PDI) & 0.340 & 0.244 \\
Zeta potential (mV) & -21.5 & -10.1 \\
\hline
\end{tabular}

*Lipid components are expressed as mol\% of total lipids 